University of Redlands

\title{
Al-Sulaiti Online Museum: A Journey Through Time
}

\author{
A Major Individual Project submitted in partial satisfaction of the requirements \\ for the degree of Master of Science in Geographic Information Systems \\ By \\ Brandon Collins Nilsson \\ Ruijin Ma, Ph.D., Committee Chair \\ Douglas Flewelling, Ph.D.
}

December 2013 
Al-Sulaiti Online Museum: A Journey Through Time

Copyright (C) 2013

By

Brandon Collins Nilsson 
The report of Brandon Collins Nilsson is approved.
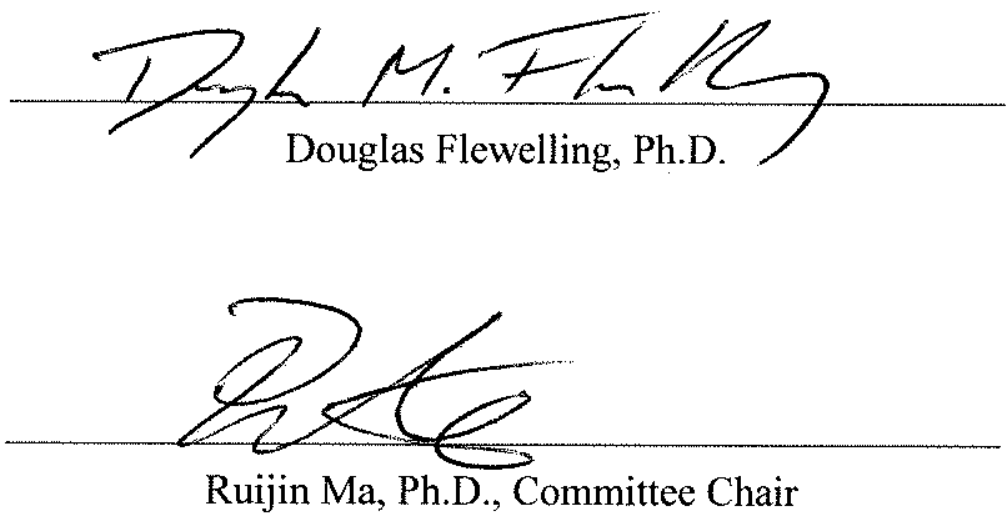

December 2013 



\section{Acknowledgements}

I would first like to thank my close friends and family for their continuous support in me to complete this master's degree at the University of Redlands. I cannot thank the MSGIS faculty and Esri staff for their guidance and knowledge of the field. Without the help I could not have come nearly this far.

I cannot thank my advisor Dr. Ruijin Ma enough for his insight and help through the completion of the project. If it wasn't for his questions and suggestions the project wouldn't of been nearly as in-depth as it is. More thanks go out to Dr. Douglas Flewelling, Dr. Mark Kumler, Dr. Fang Ren, and Dr. Russle Weaver for always asking the difficult questions and giving ideas on how to best incorporate ideas. A thank you to Ruben Ortiz for help with troubleshooting errors. One cannot forget Debra Riley for always being there for us with helpful advice and being everyone's mom when we needed it.

Special Thank You to my good friend Joe Pierce for helping me edit, and critique this entire paper. It was a great help and I cannot say thank you enough for the help. Lastly I would like to thank everyone from Cohort 22, 23, and 24 for their help, guidance, and advice as we all went through this program. 



\author{
Abstract \\ Al-Sulaiti Online Museum: A Journey through Time \\ By \\ Brandon C. Nilsson
}

Knowledge of the past comes from what has been left behind. When artifacts are found they give insight into what the world was like before. These artifacts can be used to not repeat the mistakes that were made in the past and to enlighten the present. The public desires easier access to the knowledge contained within museums. This project developed an online GIS application that makes the contents of one private collection of artifacts accessible through the Internet. This application will allow for anyone with an Internet connection to be able to view the collection or academics to perform research on its contents. 



\section{Table of Contents}

Chapter 1 - Introduction ............................................................................ 1

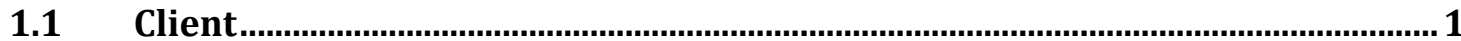

1.2 Problem Statement......................................................................................... 1

$1.3 \quad$ Proposed Solution....................................................................................... 1

1.3.1 Goals and Objectives .............................................................................................................. 2

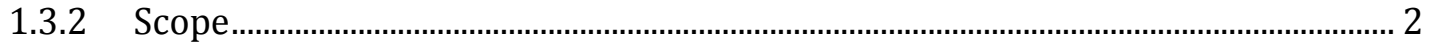

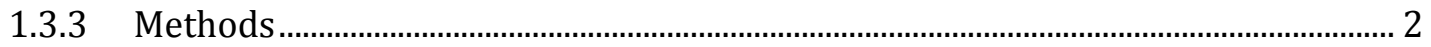

1.4 Audience ................................................................................................... 2

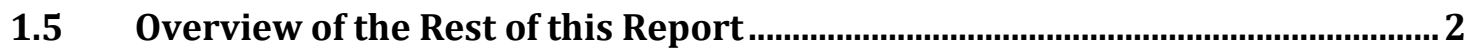

Chapter 2 - Background and Literature Review ..................................................... 5

2.1 GIS in Museums............................................................................................

2.2 GIS Solutions for Museums ……................................................................. 5

2.3 Web Programming Adobe Flex and Esri API for Flex .......................................... 6

2.4 The Future for Virtual Museums .......................................................................... 6

2.5 New Methods for Presenting Museum Objects and Information ........................ 7

2.6 Summary ...........................................................................................................

Chapter 3 - Systems Analysis and Design ……................................................. 9

3.1 Problem Statement.......................................................................................

3.2 Requirements Analysis ...................................................................................

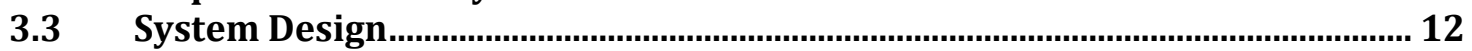

3.3.1 Application Interface.......................................................................................................12

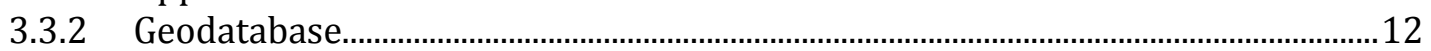

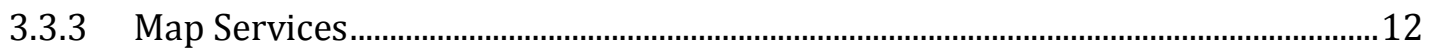

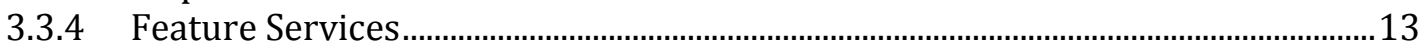

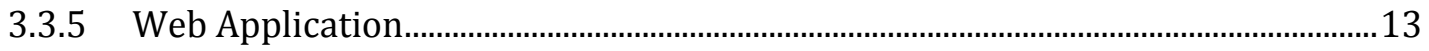

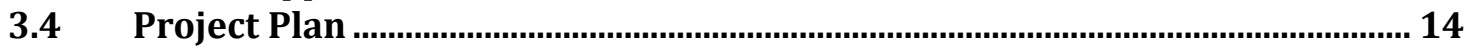

3.4.1 Requirements Analysis ...................................................................................................

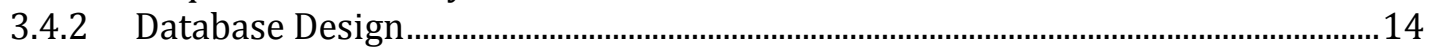

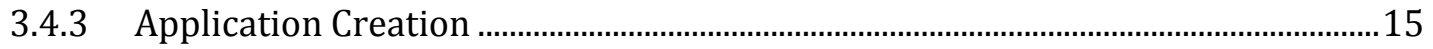

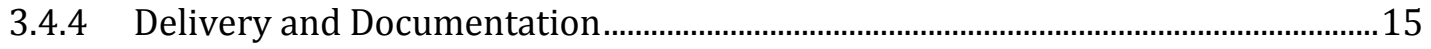

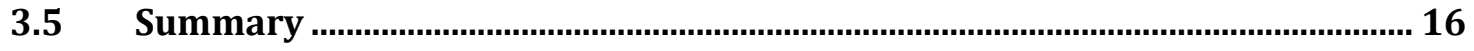

Chapter 4 - Database Design ............................................................................17

4.1 Conceptual Data Model .............................................................................. 17

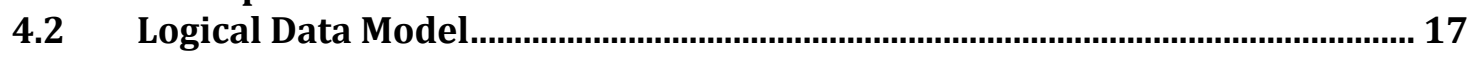

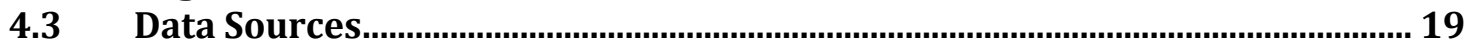

4.4 Data Scrubbing and Loading ……................................................................ 19

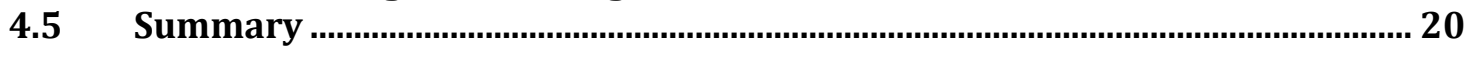

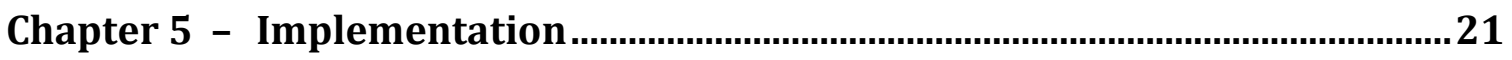

$5.1 \quad$ Database Design and Development ................................................................... 21

5.2 Data Preparation and Loading ………………................................................ 21

5.3 Webmap Application Development.................................................................. 22

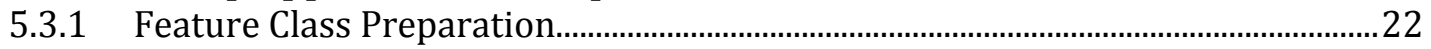

5.3.2 GIS Server Connection and Registering Data.................................................................23

5.3.3 Publishing Map and Feature Services ...............................................................................24 


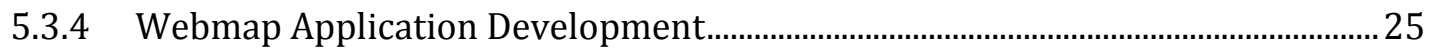

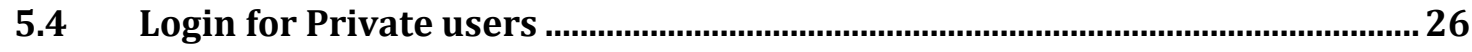

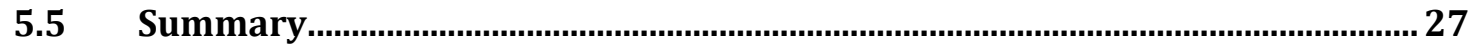

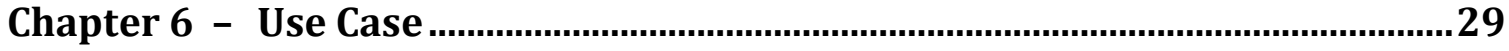

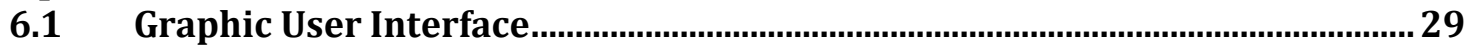

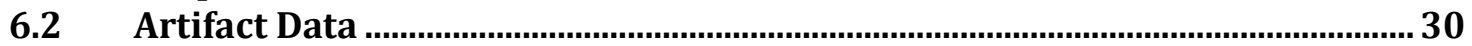

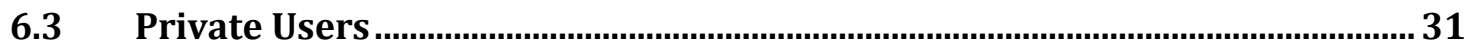

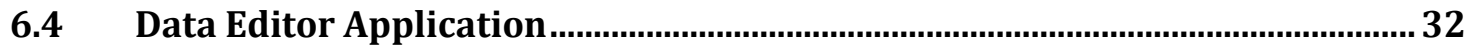

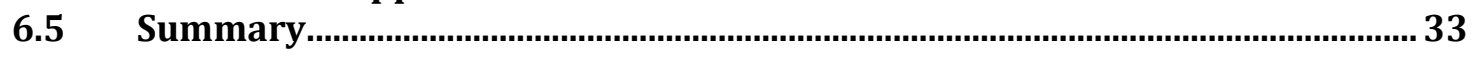

Chapter 7 - Conclusions and Future Work …..................................................... 35

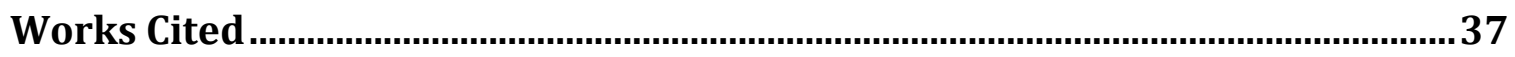

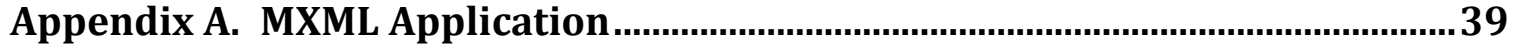

Appendix B. Feature Editor Application ..................................................................49 


\section{Table of Figures}

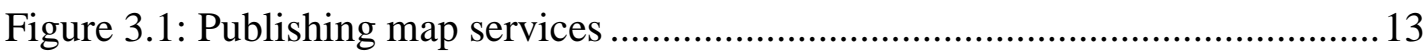

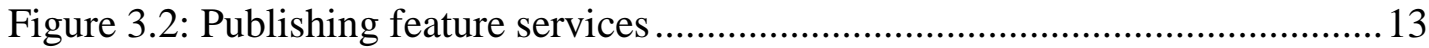

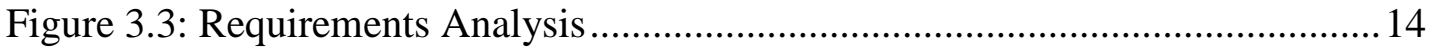

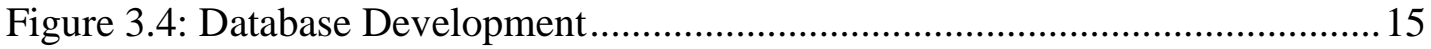

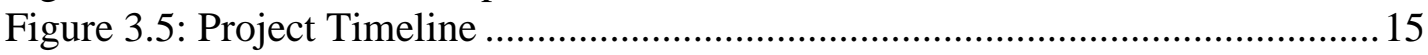

Figure 4.1: Logical Data Model ........................................................................ 19

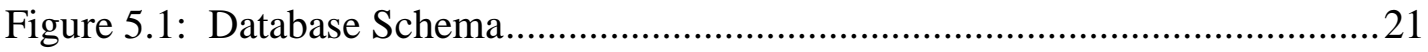

Figure 5.2: Data Loading Workflow .................................................................. 22

Figure 5.3: Feature class of sample artifacts on World Light Gray Base from Esri.. 23

Figure 5.4: ArcGIS GIS Server Connection Workflow .........................................24

Figure 5.5: Service Publishing Workflow ..........................................................2 24

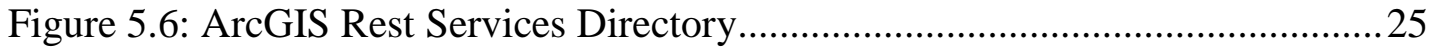

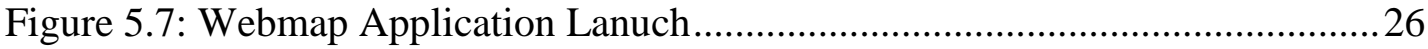

Figure 6.1: Application and Graphic User Interface.............................................29

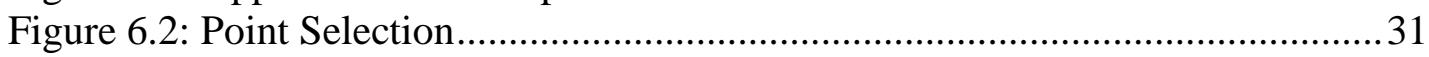

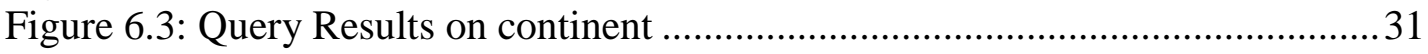

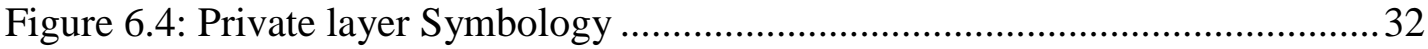

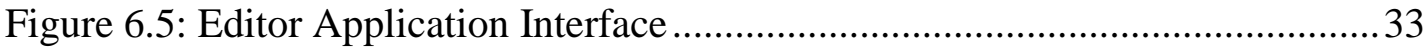





\section{List of Tables}

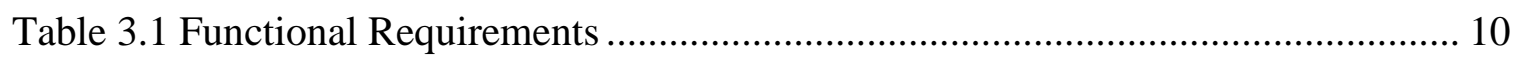

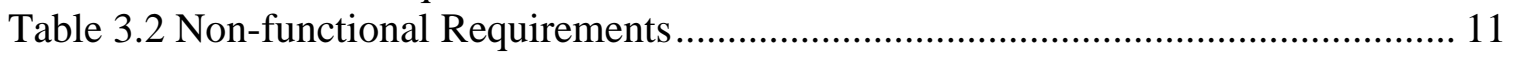

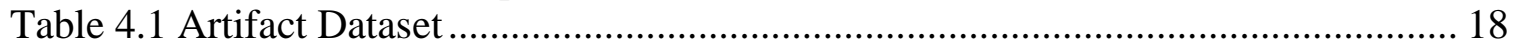

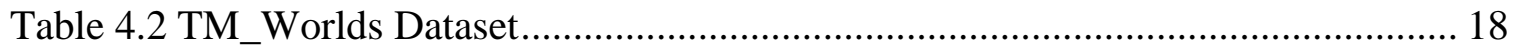

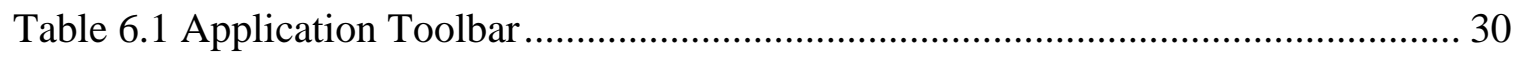





\section{List of Acronyms and Definitions}

$\begin{array}{ll}\text { API } & \text { Application Programming Interface } \\ \text { CSV } & \text { Comma Separated Value } \\ \text { GIS } & \text { Geographic Information System } \\ \text { GUI } & \text { Graphic User Interface } \\ \text { HTML } & \text { Hyper Text Markup Language } \\ \text { HTTP } & \text { Hyper Text Transfer Protocol } \\ \text { IDE } & \text { Integrated Development Environment } \\ \text { KML } & \text { Keyhole Markup Language } \\ \text { MXML } & \text { Minimal Extensible Markup Language } \\ \text { REST } & \text { Representational State Transfer } \\ \text { SDE } & \text { Spatial Database Engine } \\ \text { SDK } & \text { Software Development Kit } \\ \text { URL } & \text { Universal Resource Locator } \\ \text { XML } & \text { Extensible Markup Language }\end{array}$





\section{Chapter 1 - Introduction}

Knowledge of the past that is being preserved in museums requires the ability to access that information in order to gain insight to it. The stores of knowledge that are contained within the walls of museums accessible to the public worldwide is paramount for a more informed society. With the ever growing size and availability of the Internet access to knowledge is at the publics' fingertips. The Internet allows access to information from any part of the globe. The use of the Internet and its popularization allows for research to be undertaken from around the world.

Mohammed Al-Sulaiti is a retired petroleum engineer who had collected a wealth of artifacts during his life and wished to distribute the knowledge about them to the public. With a museum being built in Doha, Qatar for his collection a world public medium has been desired.

This chapter presents an introduction to the project and the client. The following Section 1.1 gives an introduction to the projects client; Section 1.2 addresses the problem solved by this project; Section 1.3 explains the goals, objectives, scope, and methods applied to complete and carry out the project; Section 1.4 addresses the audience for the paper; and Section 1.5 provides the outline for the remaining parts of the paper.

\subsection{Client}

The client for this project was Mohammed Al-Sulaiti, a retired petroleum engineer from Doha Qatar, who had collected artifacts throughout his life and was building a museum to house them. He needed a way to present his collection to the world from Qatar. Mohammed Al-Sulaiti was interested in using GIS to help his collection reach a broader audience. He provided a sample of his collection in Word and PDF documents with information covering each artifact.

\subsection{Problem Statement}

Mohammed Al-Sulaiti amassed a large number of artifacts but lacked a method of displaying the artifacts with the public. The problem addressed was the lack of public viewing of the museum collection from the world. The client desired an application to have a way of viewing his collection from anywhere with Internet access. With an application Mohammed Al-Sulaiti would be able to display his collection and show what he had done through his life.

\subsection{Proposed Solution}

The solution decided upon by and for the client was to create a GIS web map application for curating a museum and for the public to view its contents. The application would allow Mohammed Al-Sulaiti and the public to view and query the collection of artifacts. The scope of the project was determined to help in the success of the project. The methods used to reach the goals of the project are elaborated on in the proceeding section. 


\subsubsection{Goals and Objectives}

The goal of this project was to aid Mohammed Al-Sulaiti in displaying the information he had collected adequately and effortlessly to the public. The primary objective was to create an easy to understand and use GIS web application to streamline the display of information. Additionally, this project was to help the client manage the digital information of his collection. Three objectives were discerned for the project to accomplish the goal. The first was to geo-locate the artifacts based upon the nation where they were found. The second was the creation of a geodatabase to house the datasets for the project. The third was using the data provided by the client to create an interactive web application for maintaining and viewing his museum collection.

\subsubsection{Scope}

The scope included converting Microsoft Word and Adobe PDF documents and convert them to a GIS format and geo-locating each artifact individually at a nation level. A dataset containing the boundaries for all the nations of the world was collected. This world dataset was combined to give more in depth information on each artifact and was loaded into a file geodatabase. The completion of data collection allowed for the development of the web application. The web application was created to be simple to use and informative with Adobe Flash Builder and ArcGIS API (Application Programming Interface) for Flex. With the developed application it allowed Mohammed Al-Sulaiti and the public to view the museum contents. This allows users to look into the past and conduct private research.

\subsubsection{Methods}

This project incorporated varying techniques and methods in each stage of development. For system analysis and design, similar projects were studied, and ideas were spoken with the client to decide what medium to use and the definition of requirements.

Conceptual and logical data models were created to determine what data alongside the provided data to build the database schema. A geodatabase was designed and the data was imported.

A GIS web application was created with Adobe Flash Builder, Flex SDK 4.6, and ArcGIS API for Flex version 3.4. This process required map services and feature services to be published to an ArcGIS 10.1 for Server with SDE using ArcGIS Desktop 10.1

\subsection{Audience}

The intended audiences for this paper are individuals trying to figure out how to create an application that is similar to this. This also includes individuals with knowledge of GIS and/or programming.

\subsection{Overview of the Rest of this Report}

This report includes seven chapters, which describe how the project was carried out. Chapter two presents a literature review of past works that were similar to the use of GIS 
in/for museums. Chapter three describes the system analysis and design process of the project. Chapter four goes over database design, including conceptual and logical database models, and data formatting and loading. Chapter five details how the project was implemented. Chapter six provides use cases of the developed application. Chapter seven summarizes the project and speculates possible ideas for future work related to the project. 



\section{Chapter 2 - Background and Literature Review}

With the evolution and accessibility of the Internet, Geographic Information Systems knowledge about the world has become straightforward to come by. This chapter is divided into four sections starting from Section 2.1 which reviews work done in the field of GIS for museums; Section 2.2 goes over GIS solutions for museums. Then Section 2.3 provides a brief overview of web programming languages, focusing on Adobe Flex and action script, and Esri's Application Programming Interface (API) for Flex. Section 2.4 examines the future of museums online. Section 2.5 goes over new methods on how to present objects and information contained in museums. Lastly Section 2.6 recaps the chapter.

\subsection{GIS in Museums}

"The Benefits of studying existing museum collections... is well demonstrated and enhanced by applying spatial analysis through the use of mapping technologies like geographic information systems" (Woert, 2011, p. 17). The idea of using GIS in museums is not new, but a fear of technology and the cost has limited the integration. A Museum focused GIS was used to identify locations where artifacts could be found based upon those already obtained and added to the collection. GIS technology was developed in different ways based upon the application but "... archaeology has been one of the primary beneficiaries of this surge..." (p. 18) for museums. Using the framework, archaeologists can identify areas where more artifacts can be found.

The use of modern technology and the prevalence of the Internet have immensely changed how people go about their days. "This also applies to museology. Today many museums of the world have their own websites on which users can receive [information on exhibitions]" (Mikhailovna \& Vikentevich, 2004, p. 217). These websites were used to bring the knowledge contained within the walls of museums closer to the people who cannot visit the site directly. "Museums are constantly looking for new ways to make their collections or information about them more accessible to general and specialist users." (Boyd, 2002) The use of GIS technology has the ability to provide information that might not normally be seen.

\subsection{GIS Solutions for Museums}

GIS technology allows web based users to view "Collections of natural specimens and man-made objects are the key component of a museum and it is essential that a museum knows what items it has, where they came from, where they are now, who they belong to and their significance" (Boyd, 2002). The technology allows better access to information about museum collections, boosts interpretation of displayed artifacts, and is an avenue of introduction for users who cannot visit the museum physically due to illness, disability, or being in a different nation/continent from the museum. The Carnegie Museum of Natural history used geographic information systems "as a tool that can connect many fields of research" (Powdermill Nature Reserve, 2006). This approach allowed for "expand[ed] research capabilities for museum staff, research associates, and students" (Powdermill Nature Reserve, 2006). 
With the use of GIS and planning techniques, services for tourists can be created. Dynamic maps at the request of a user displayed monuments, allowed for future planning and development of museum land, and routed through a city to browse natural or historic areas. "The users of such a GIS are various enough, including departments of regional administrations on culture and tourism, tourist enterprises, and ordinary citizens who wish to choose suitable tourist routes" (Mikhailovna \& Vikentevich, 2004, p. 217).

\subsection{Web Programming Adobe Flex and Esri API for Flex}

The technological expansion of web GIS is because of the growth of web services. The interactivity between these two technologies aided in the transformation of web GIS applications. The development and non-stop growth of Rich Internet Applications (RIA) are paving the way for high performance and efficiency in executing code and displaying graphic content. Adobe Flex was designed to be developer friendly with web applications which run within web browsers with Adobe Flash Player plugin installed. Adobe Flex leverages Minimal Extensible Markup Language (MXML) to enhance controls and provides in depth data display. MXML is an XML based language developed with ActionScript. Esri has developed several web mapping APIs including ArcGIS API for JavaScript, Flex, and Silverlight, which provide a developing environment for web map applications. The ArcGIS API for Flex is built atop Adobe Flex framework which allows access to Flex based components. The Flex API allows for geoprocessing and map display within Adobe Flex framework such as displaying interactive web maps, geocoding, reverse geocoding, data combination, and editing.

\subsection{The Future for Virtual Museums}

"The face of virtual on-line museums is entering another period of change" (Jones \& Christal, 2002, p. 1). This period of change sought to create an in-depth environment that placed the museum patron in a portrayal of the museum. Headed by the Smithsonian Institution National Museum of the American Indian, a virtual tour was created with collaboration from the US Department of interior Bureau of Indian Affairs. The virtual tour was different because "students from Indian schools participated actively in the creation of the content and added their own first-hand knowledge of the artifacts" (p. 2). The individuals who participated in the creation of content for the museum used QuickTime Virtual Reality and recorded virtual objects. The recordings included panoramic views in exhibition halls and research accompanying the museums artifacts. These recordings and research were hosted on the virtual tour web page. The web page allowed for individuals with Internet access to 360-degree panoramas and immersion for exhibit halls for visitors. "The [Nation Museum of the American Indian] site is a good example of a medium level web-based virtual museum" (p. 2).

An example of a more sophisticated web site that used more advanced imagery is the Virtual Smithsonian. The exhibits used the same QuickTime Virtual Reality but in conjunction with high-resolution images, videos, and audio clips for a greater depth of immersion. At the time the Virtual Smithsonian was created it was difficult to use because of the lack of high-speed Internet connections in the United States. With advancements in Internet bandwidth and accessibility, the Virtual Smithsonian shows "the potential for presenting a diverse collection of materials to people that might never 
have the chance to visit the actual museums" (Jones \& Christal, 2002, p. 3). With the constant advancement of computing technology, a 3D museum for outside visitors is to become a reality.

\subsection{New Methods for Presenting Museum Objects and Information}

The use of the Internet has become commonplace in households. With the Internet becoming a leading method to display information, museums started to recognize the possibilities available to the public. "A museum can be defined as a nonprofit institution that collects, preserves, and displays objects for educational or aesthetic purposes" (Schweibenz, 1998, p. 187). The communicative ability of museums draws parallels between museums and the media. Roger Silverstone stated that "museums are in many respects like other contemporary media. They entertain and inform; they tell stories and construct arguments; they aim to please and to educate; they define, consciously or unconsciously; effectively or ineffectively, an agenda; they translate the otherwise unfamiliar and inaccessible into the familiar and accessible" (Schweibenz, 1998, p. 187). The obvious differences in museums and media were museums occupy space in the world and house artifacts with an emphasis on interactivity. The interactivity is not available from media.

During the 1980s a shift occurred in museums revolving around the importance of objects in the favor of the information about the objects. Museums were described by George MacDonald and Stephan Alsford as information utilities, even stating that museums should think of information over their respective collections as an important resource. Museum studies were conducted on visitor interests, and the growing importance of education was shown. Museums took the step forward in education by establishing context behind the presented objects to connect to visitors. This idea changed the museum from collection-driven to more emphasis on the audience the museum caters to. The focus of the museum started to reach out to prospective visitors and research into the outreach services for the museum to link with its visitors. "For them, the Internet seems to be the ideal knowledge base and communication system to achieve this goal" (Schweibenz, 1998, p. 189). The use of the Internet allows for the linking of text, images, audio, and video to an interactive media environment. The Internet environment provides limitless opportunities for museums to display their collections and educate their visitors either remotely via the Internet or at the physical location.

\subsection{Summary}

The primary goal of this project was to develop a web map application to allow for the display of a collection of artifacts to the public. Section 2.1 explained the use of GIS in museums studying their collection. Section 2.2 examined the solutions that GIS technology brings to museums and the benefits that come with it. Section 2.3 reviewed the potential of Adobe Flex and the Esri API for Flex in the design and creation of web map applications. Section 2.4 went over the early beginnings of virtual museums and focused on the National Museum of the American Indian and the Virtual Smithsonian. Section 2.5 explained the parallels between museums and the media and how museums used the media to change how education occurred at their locations or on the Internet 



\section{Chapter 3 - Systems Analysis and Design}

To gain the knowledge to provide the best applicable solution to the clients' problem, questions were asked and discussions occurred to garner an agreement on the end product, and public and private user requirements. The project began with examining current use of GIS in museums and the steps used to implement the technology. As project progression gained momentum thorough designs were made for components to be used by the application. This chapter contains five sections. Section 3.1 reiterates the problem being addressed. Section 3.2 describes the functional and non-functional requirements of the project. Section 3.3 explains the system design. Section 3.4 goes over the project plan and Section 3.5 summarizes the chapter.

\subsection{Problem Statement}

The client collected a massive amount of artifacts but lacked the ability to present this collection to the world's public. His data were contained in Word and PDF documents. Mohammed needed a medium to enable the public to view his collection without having to visit his museum. Such an application would enable the public to easily view his entire collection from anywhere with an Internet connection. This web application could encourage other museums to follow suit to enable the world public to view their collections from the Internet.

\subsection{Requirements Analysis}

Functional and non-functional requirements were determined for the project with the client. The functional requirements of the application were comprised of functions that captured users' needs and that were interacted with directly. These requirements came from phone calls and emails with Mohammed Al-Sulaiti to cater to the desires for the final product. Functional requirements, listed in Table 3.1, were the inputs, behavior, and outputs of the application upon use.

Non-functional requirements, presented in Table 3.2, were those that were not directly interacted with by users but were the backbone for the developed application to perform successfully. They described user-friendly interfaces and application constraints. 
Table 3.1: Functional Requirements

\begin{tabular}{|l|l|}
\hline Private user authentication & $\begin{array}{l}\text { Login with a username and password } \\
\text { for viewing the private section of the } \\
\text { collection }\end{array}$ \\
\hline Public map service & $\begin{array}{l}\text { Pop-up artifact information } \\
\text { Chart differences in number of artifacts } \\
\text { between nations }\end{array}$ \\
\hline Private map service & $\begin{array}{l}\text { Pop-up artifact information that public } \\
\text { users cannot see. }\end{array}$ \\
\hline Create new data record & $\begin{array}{l}\text { Pop-up artifact information that is } \\
\text { editable. Update names, locations, and } \\
\text { information. }\end{array}$ \\
\hline Basemap & $\begin{array}{l}\text { Aquired from ArcGIS online. Light grey } \\
\text { canvas basemap }\end{array}$ \\
\hline Database & $\begin{array}{l}\text { Contain data on artifacts joined with } \\
\text { ArcServer with SDE (Spatial Database } \\
\text { Engine) }\end{array}$ \\
\hline
\end{tabular}


Table 3.2: Non-functional Requirements

\begin{tabular}{|l|l|}
\hline Adobe flash player & $\begin{array}{l}\text { Flash player 11 plugin latest version or } \\
\text { higher }\end{array}$ \\
\hline Esri API for Flex & ArcGIS API for Flex 3.4 \\
\hline Map services & $\begin{array}{l}\text { Public, private and editor published } \\
\text { versions and hosting of map services }\end{array}$ \\
\hline Feature services & $\begin{array}{l}\text { Public, private and editor published } \\
\text { versions and hosting of map services }\end{array}$ \\
\hline Web domain & a domain name for Internet hosting \\
\hline
\end{tabular}

There were five different functional requirements for the project: private user authentication, public map section and private map section after authentication, a map for editing, inverse geocoding to aid in editing, and the selection of basemap. It was highly emphasized that the application had to split the collection into public and private sections for two groups of users. Only individuals trusted by the client would be allowed to view more of the collection compared to public users. The developed database contains the login credentials for private users. The public and private maps allow users to interact with the services published with ArcGIS for Server. The main functionality of the application includes: pop-up of artifact information and queries to show the number of different artifacts between continents. The pop-up function allows users to click a point on the map and read information about the point representing an artifact. Users can also use a standard geocoding feature to explore the map through areas they know. The query functionality allows a user to select the continents desired to show the spread of artifacts. The editor is capable of adding new points on the map with information pertaining to the artifact being added.

Non-functional requirements defined database configuration and schema, software requirements, and user interface. For editing information that was contained in the map, it required ArcServer with SDE. The project hosted all crucial services on the ArcGIS Server at the MS GIS Program. Development of the desktop GIS application using the 
ArcGIS API for Flex required ArcGIS Server with SDE and ArcGIS online. A simple and easy to use interface was highly emphasized for the application by the client.

\subsection{System Design}

The linchpin of the system design was made with the functional requirements, nonfunctional requirements, and conversations with the client. The information helped design and implementation of the geodatabase, creation of the GIS web application, and the published services stored in the GIS server. The web application, held on a web server, communicated with ArcGIS Server with SDE via a browser with Adobe Flash Player installed.

\subsubsection{Application Interface}

The design for the user interface required components that were put forward during the design phase and critiqued during implementation. The view that is first seen by users is the start-up view. Following the use of the application, the operational view is displayed. When the application runs it shows the main toolbar that contains the navigation tools, geocoding text box, artifact table button, and private user login boxes.

\subsubsection{Geodatabase}

The geodatabase is a storage container and management interface in ArcGIS that allows the extension and expansion of data. For this project point feature classes were made in ArcMap 10.1 and brought into a multi-user ArcServer Geodatabase. This decision was based on the requirements for the project. The information contained within the geodatabase was later used in creating and publishing services with ArcServer with SDE. The file geodatabase, default used by ArcSDE for services, had a higher capacity compared to the other formats and enabled the client to update and add information in the future.

\subsubsection{Map Services}

Map services were the containers of geographic information that could be used and visualized over the Internet. The services were published using ArcGIS desktop to ArcServer and put to use by the web application on the user end. Map services allowed for the viewing and querying of content. Feature services used by editors allowed editor tracking, updating, adding, and deleting information. The file geodatabase was used to manage the data contained in the map and feature services which were published to the server using Representational State Transfer (REST) service. Figure 3.1 explains the process of publishing map services. 


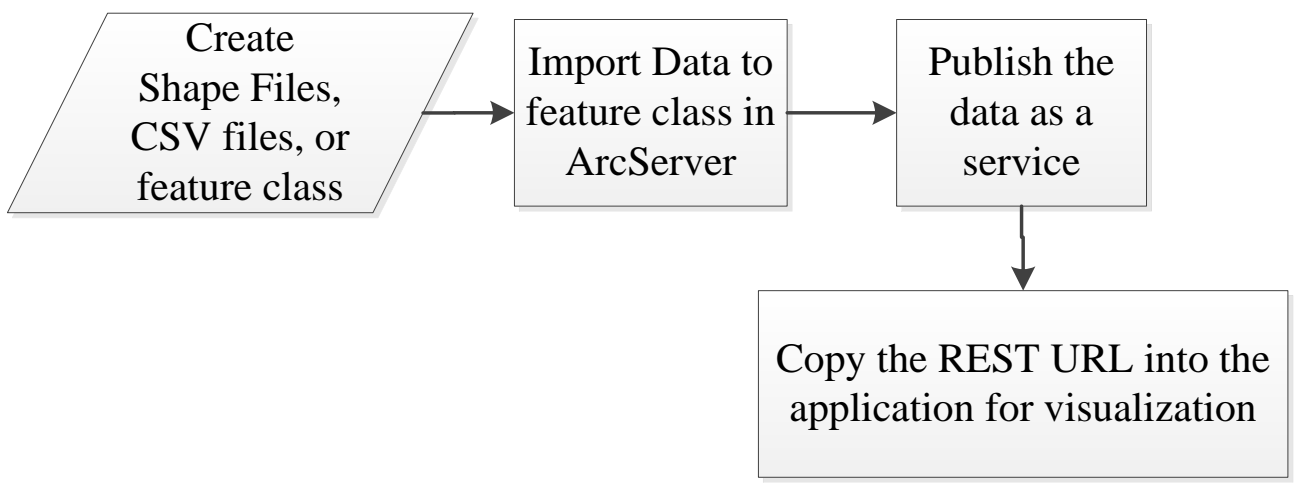

Figure 3.1: Publishing map services

\subsubsection{Feature Services}

Feature services, like map services, were containers of geographic information that could be used and visualized over the Internet and edited if the capability was enabled. Unlike map services, feature services must have feature classes on an ArcServer with SDE to enable feature access. With feature classes on an ArcServer with SDE, they must have been versioned to accept edits and were then ready for publishing. The file geodatabase was used to manage the feature classes for the services in the map and were published to the server using a REST service. Figure 3.2 explains the process of publishing a feature service.

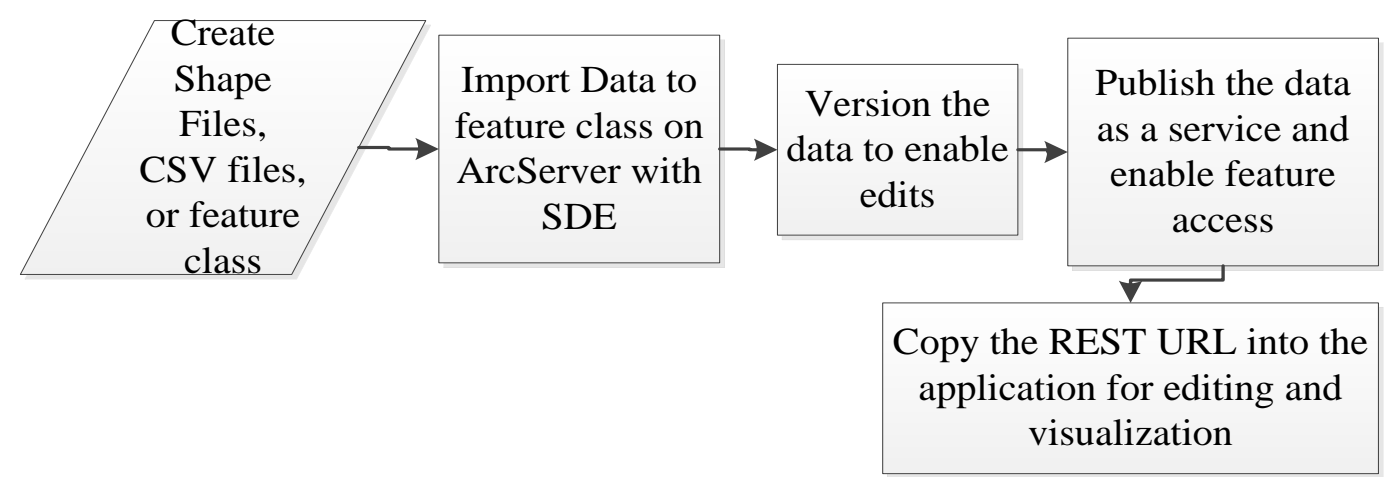

Figure 3.2: Publishing feature services

\subsubsection{Web Application}

Using the ArcGIS API for Flex 3.4 with Adobe Flash Builder 4.6, an extensive web application was developed for the client and users. The application used the services published to ArcServer with SDE and the basemaps from ArcGIS Online.

A requirement for users to view the information on the website was that they need to have the latest version of Adobe Flash Player plugin for their respective browser. With the application live, users would be capable of viewing the collection of artifacts from around the world, and view the spread of the artifacts across the continents. 


\subsection{Project Plan}

The project plan included the following five phases: requirement analysis, database design, application creation, documentation, and delivery. The requirement analysis phase was comprised of defining the components necessary for the project and the clients' desires, functionality, and what the clients' system needs to maintain the application. System design phase included the functional and non-functional requirements. The application creation phase was made up designing and configuring the web application to be user-friendly, and developing the functionality requested by the client.

\subsubsection{Requirements Analysis}

Several phone conversations were held with Mohammed Al-Sulaiti to determine the requirements of the project. To create a detailed definition of the projects deliverables system requirements and the scope were focused on. Prior to data being delivered from the client, Mohammed Al-Sulaiti reviewed the data in his possession to aid in the collection of outside datasets. Figure 3.3 illustrates the workflow for requirements analysis. With the client aiding in the completion of this task it kept the project on track for completion.

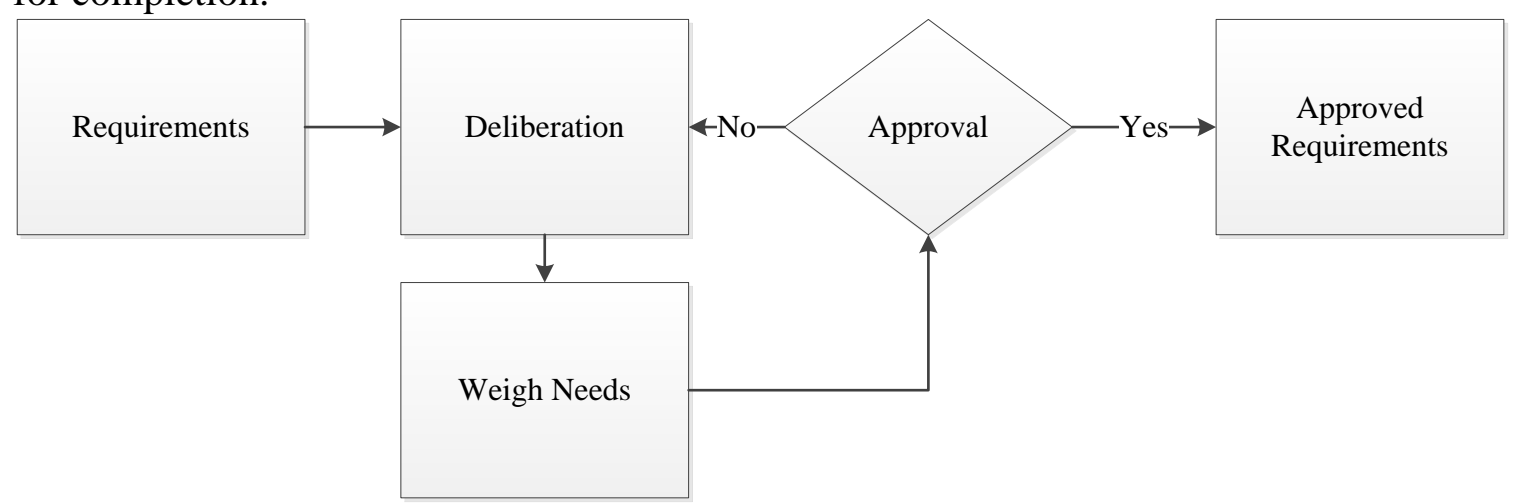

Figure 3.3: Requirements Analysis

\subsubsection{Database Design}

Following the completion of the project requirements, database design commenced as illustrated in Figure 3.4. A conceptual data model was used to understand the organization of the data. The process of designing the database took less time than projected. This was because the data provided by the client was clear and comprehensible. These allowed for more time being put into the rest of the project and not cause any delays. 


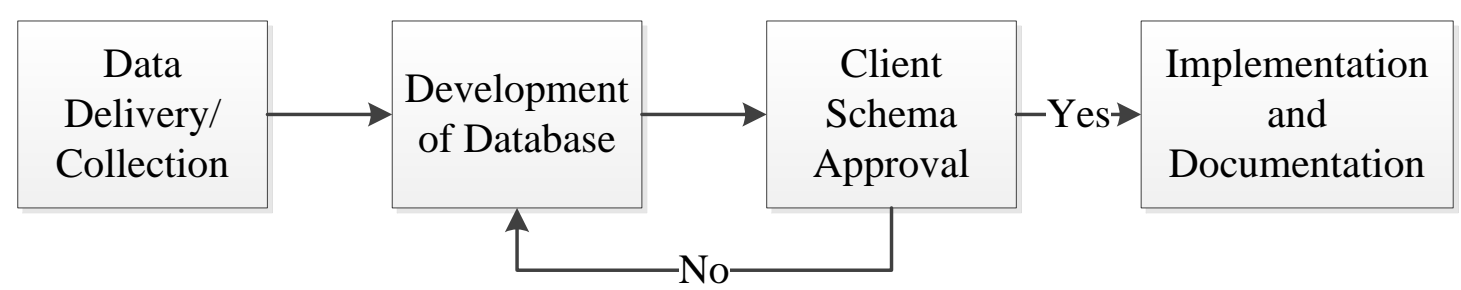

Figure 3.4: Database Development

\subsubsection{Application Creation}

Application development included a number of tasks from acquiring the necessary software, and web service publishing access. ArcGIS 10.1 for server was used for publishing and hosting web services. The use of ArcGIS 10.1 Server allowed for testing features, visualization, and querying to address any potential issues and finally published for consumption. The creation of the application was completed ahead of schedule because of the sample pages provided by Esri, and a training course held online by an Esri instructor.

\subsubsection{Delivery and Documentation}

Documentation was a process that was done in parallel with system design and application creation to make a thorough document on how the project was completed. A report on the breakdown of each task was completed. The completed project was delivered to the client with the documentation on each piece. The final phase of delivery was done by setting up the connection to the servers and putting the web application on a web domain to be accessed from around the world via Internet.

Through the development lifecycle, some tasks were moved forward in the project plan. The timeline was shortened and extended for some components. This changed the scope slightly and the project was completed. Figure 3.5 breaks down the timeline of the project.

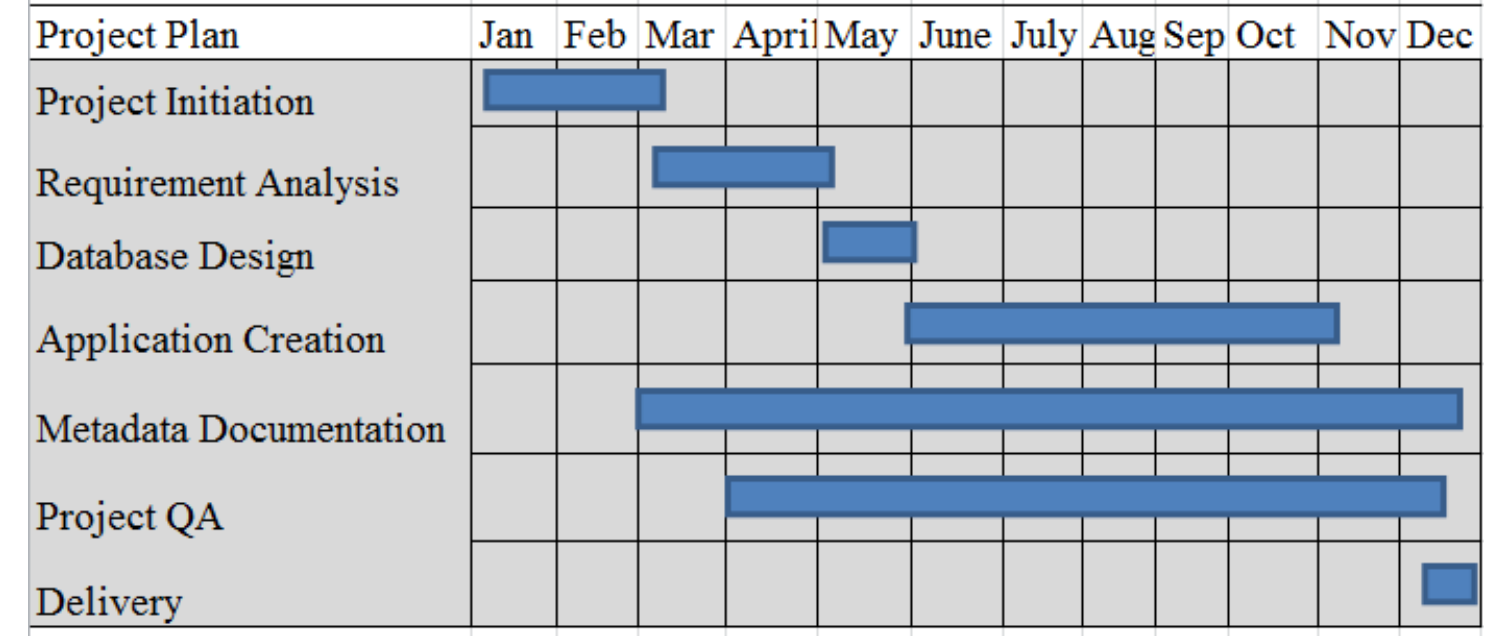

Figure 3.5: Project Timeline 


\subsection{Summary}

This chapter summarized the clients' problem, scrutinized the functional and nonfunctional requirements, displayed the process of system design for the project, and went over the plan for the project. The client needed a way to present his collection to the public. The project was built on the grounds that these things were going to be purchased but not necessary in completion. With this idea in mind the application was developed to incorporate services from ArcGIS Online in the same manner when they were hosted to ArcGIS Server. The web application would use the services in the same manner with the user of the Internet. 


\section{Chapter 4 - Database Design}

A well-designed database was the first step towards success in the project. For this project the database was designed to be effective at managing artifacts, ease of maintenance, and visualization/retrieval of information. This chapter elaborates the steps taken in database design and the process of implementation of this project. Section 4.1 explains the conceptual data model which describes the framework and links in the data. Section 4.2 explains how the conceptual model was used with the logical model in making a GIS database. Section 4.3 goes over where the data came from. Section 4.4 examines how the data was prepared for being input into the geodatabase for the project. The chapter is summarized in section 4.5.

\subsection{Conceptual Data Model}

The conceptual data model was an essential piece to the project. It was created from emails and phone conversations with the client of the project. The information derived from these emails and conversations identified how data should interact and what other datasets were going to be needed to create a solution for the clients' problem. The classes that were finalized for the project were Artifact and WorldNations. The Artifact class had a many to one relationship with the WorldNations class. The relationship was based off of the nation where each artifact, in the Artifact class, originated from. This relationship allowed for many artifacts to be contained within the boundary of a single nation. The WorldNations class contained an up to date list of the nations in the world

\subsection{Logical Data Model}

The logical data model created the frame for the physical design and the process of implementing the database for the project. It held the attributes, relationships, and unique identifiers of all the features illustrated in the geodatabase. The project included three feature classes contained in an ArcGIS File geodatabase. Table 4.1 describes what information each field contains and Figure 4.2 shows what both feature classes look like. 
Table 4.1: Artifact Dataset

\begin{tabular}{|l|l|}
\hline Name & Artifact \\
\hline Nation & $\begin{array}{l}\text { The nation where the artifact was found in } \\
\text { the world }\end{array}$ \\
\hline Information & Descriptive information about the artifact \\
\hline Year acquired & $\begin{array}{l}\text { The year the artifact was acquired by the } \\
\text { client or the year it was found }\end{array}$ \\
\hline Nation acquired & Where the artifact was bought from \\
\hline Auction nation acquired & Nation where the auction was held \\
\hline Latitude & Degrees north or south of the equator \\
\hline Longitude & Degrees east or west of the prime meridian \\
\hline
\end{tabular}

Table 4.2: TM_Worlds Dataset

\begin{tabular}{|c|c|}
\hline Name & Name of the nation \\
\hline Latitude & Degrees north or south of the equator \\
\hline Longitude & Degrees east or west of the prime meridian \\
\hline FIPS & FIPS 10-4 Country Code \\
\hline ISO2 & ISO 3166-1 Alpha-2 Country Code \\
\hline ISO3 & ISO 3166-1 Alpha-3 Country Code \\
\hline UN & ISO 3166-1 Numeric-3 Country Code \\
\hline Area & Land area, FAO Statistics (2002) \\
\hline Region & $\begin{array}{l}\text { Macro geographical (continental region), } \\
\text { UN Statistics }\end{array}$ \\
\hline Sub-region & Geographical sub-region, UN Statistics \\
\hline POP2005 & $\begin{array}{l}\text { Population, World Population Prospects } \\
\text { (2005) }\end{array}$ \\
\hline
\end{tabular}




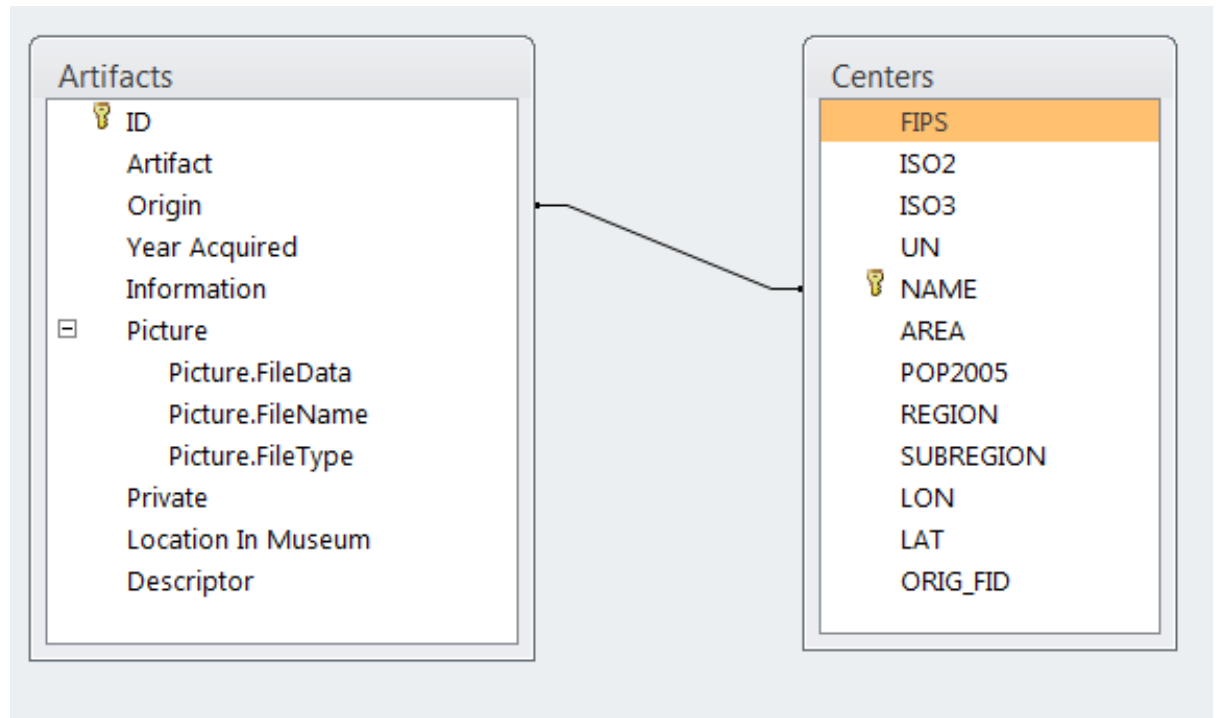

Figure 4.1: Logical Data Model

The Artifact class contains the artifact dataset. This information was used to create point features when the relationship is formed with the centers dataset. The Centers dataset contains detailed information about the nations of the world. The information that was needed for this project was the definition of the center, by latitude and longitude, of each nation and their respective names.

\subsection{Data Sources}

The datasets used in this project were acquired from two different sources. The artifact dataset was created by hand from the Microsoft Word and Adobe PDF documents provided by the client about artifacts from his collection. The Word and PDF documents contained relevant information about each individual artifact.

The TM_WORLD_BORDERS-03 dataset was downloaded, and renamed to Centers. This dataset provided the ability to map out each artifact with the nation where it originated from. This was done by using the latitude and longitude values that were provided in the dataset.

\subsection{Data Scrubbing and Loading}

Moderate cleaning and extensive preparation of the data, provided and created, were needed before loading into the geodatabase. The artifact dataset was created by hand from the information provided by the client. The artifact dataset required specialized formatting and conversion to be used in the developed ArcGIS application.

The original data provided by the client was input by hand and tested. With the recording process finalized, the values capable of input were restricted to what each section required. The point feature class was created from joining the artifact dataset with the centers based upon the nation where each originated from a one-to-many-relationship. 
After the creation of the point feature class it was loaded into a geodatabase which was then put on an ArcServer with SDE. After the loading process, map services for the public and feature services for editing were created. These capabilities were leveraged with the implementation of ArcServer with SDE

\subsection{Summary}

This chapter explained how the project molded the information provided by the client for a solution to be used in an application. The conceptual model aided in identifying the contents of the database. The logical data model was used to describe the design and implementation of the database. The chapter ended with a description of the data sources and the process of cleaning and loading the data into the geodatabase. 


\section{Chapter 5 - Implementation}

The implementation process for this project was comprised of the completion of a series of steps to meet the needs of the project and the client's requirements. A custom made web mapping application was designed for Mohammed Al-Sulaiti which allowed his collection to be viewed by the public.

This chapter explains the process of how the project was implemented in three sections. Section 5.1 explains the database design and development. Section 5.2 examines the web application design. It also elaborates on the process of preparing the datasets and the publishing of map services and feature services from this data. Section 5.3 summarizes the chapter as a whole.

\subsection{Database Design and Development}

For this project the first step in implementation was database development. An Esri File Geodatabase was chosen for the project to contain the spatial and non-spatial data. The database was created following the principles of relational database management systems. This system took advantage of storing, querying, and manipulating data for the project. The ArcGIS Diagrammer tool was used in the creation, analysis, and editing of geodatabase schema. Figure 5.1 provides the outline of the geodatabase that was made for the project.

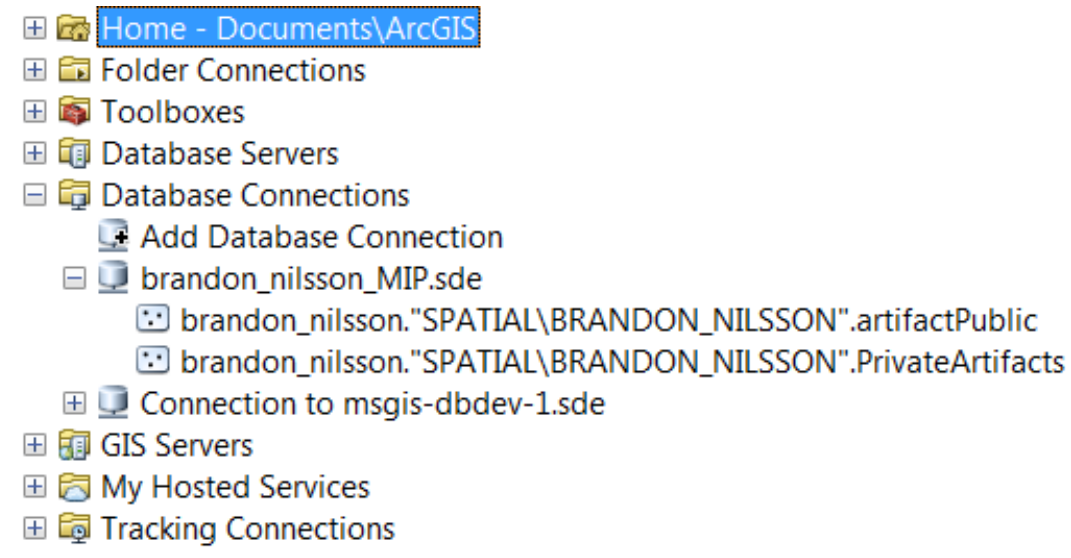

Figure 5.1: Database Schema

\subsection{Data Preparation and Loading}

The data received from the client was provided in individual Microsoft Word Documents and Adobe PDF. The data was recorded and prepared using Microsoft Access. An empty point feature class was created with corresponding fields and values. The data in the Microsoft Access database was exported as a comma separated value (CSV) file so it could be imported into the ArcGIS environment. The CSV file was then loaded into the empty point feature class for visualization. With the data loaded into the point feature class, it was then transferred into the ArcServer Geodatabase with SDE. The process of importing the point feature class to a database used the Feature Class to Feature Class 
geoprocessing tool within ArcGIS desktop. The layers were projected to WGS 1984 Web Mercator (Auxiliary Sphere) coordinate system so that they will align properly when used with the basemaps. Figure 5.2 showed the process of importing CSV files into feature classes and then into a geodatabase.

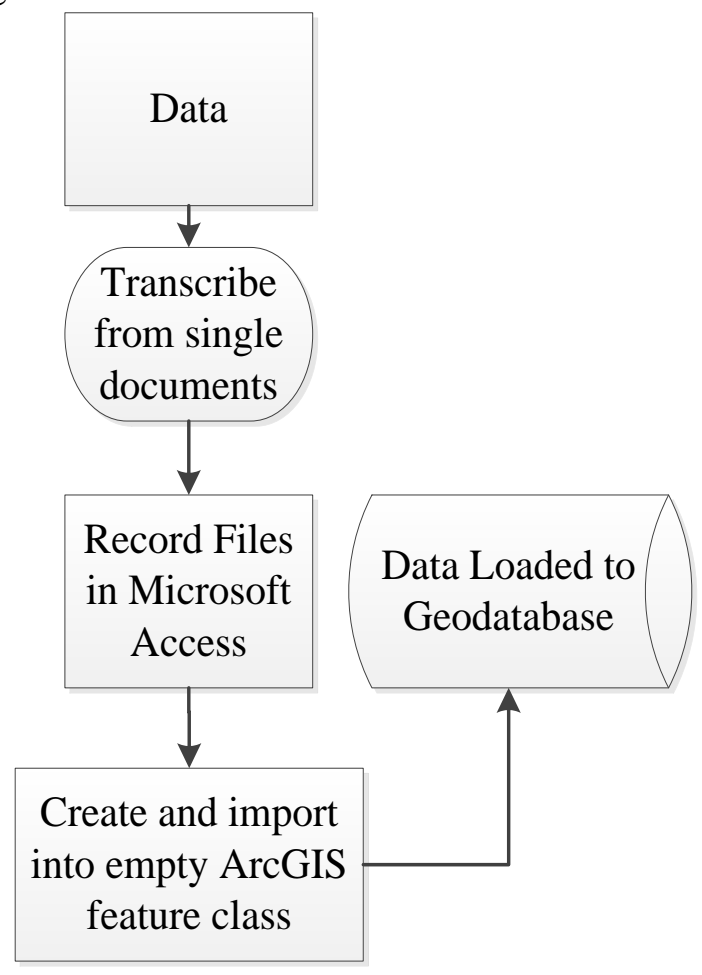

Figure 5.2: Data Loading Workflow

After the data were contained in the geodatabase, each individual artifact was geocoded to their respective location on the earth's surface using their respective latitude and longitude, which were obtained by clicking a point on an ArcGIS Online basemap. The coordinate system was set to WGS 1984 Web Mercator (Auxiliary Sphere).

\subsection{Webmap Application Development}

The focus of this project was to develop a way of delivering Mohammed Al-Sulaitis' collection to the public outside of Doha, Qatar. The Adobe Flex framework was chosen to create an interactive Internet application with data visualization, dynamic updates, background data loading. This section explains the workflow that was adhered to in the development of the webmap application.

\subsubsection{Feature Class Preparation}

With the geodatabase completed, map services and feature services were published to an ArcGIS server with SDE. ArcGIS 10.1 was used to create the map services and feature services from data contained on the GIS server. The definition of the coordinate system, the visible scale range of the feature layers, and the symbology were important for each feature class, the map services the and feature services. Public and private feature classes 
were created for both map services and feature services. Figure 5.4 shows the layers on top of a world basemap. The minimum viewing scale for each layer was not set because each dataset encompassed the entire world. The ArcGIS online basemap was used in ArcMap to help with aligning points and locating areas for future artifact placement. The basemap was removed from the map document prior to publishing the data to the GIS server.

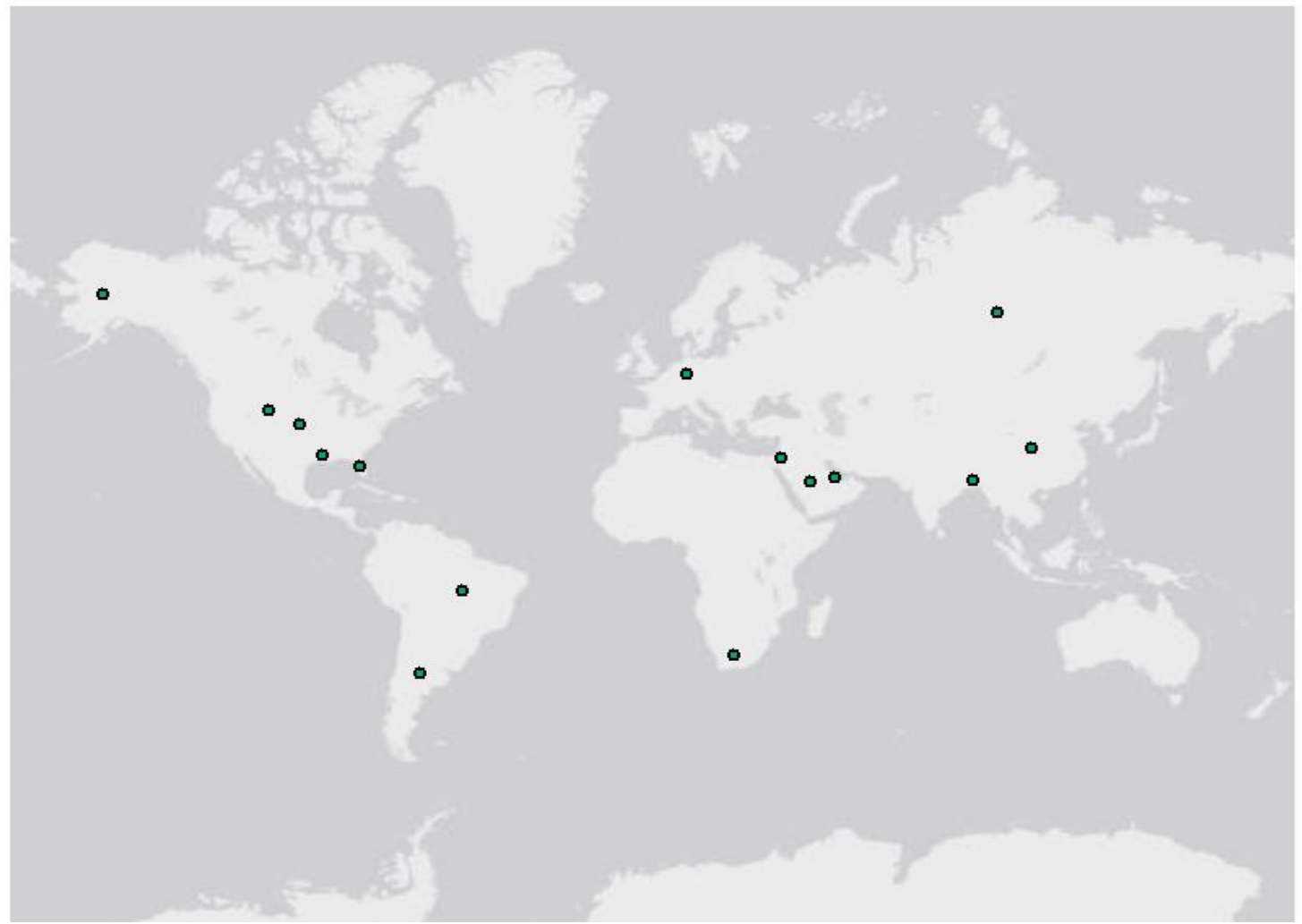

Figure 5.3: Feature class of sample artifacts on World Light Gray Base from Esri

\subsubsection{GIS Server Connection and Registering Data}

Prior to publishing the feature classes as map services and feature services, a connection to the GIS server was established. Using ArcCatalog 10.1 the connection to ArcGIS Server was created which allowed for the publishing of the data. The process of connecting allowed for the previewing and error checking of services that were to be published.

The process of connecting to ArcGIS for Server was started in ArcCatalog or could be done in ArcMap. With the add database connection under Database Connections the process started. It asked for the platform type which consists of the common database platforms used in business, required an instance name, and authentication. Authentication to ArcGIS Server was managed by the operating system. Figure 5.5 shows the database connection process. 


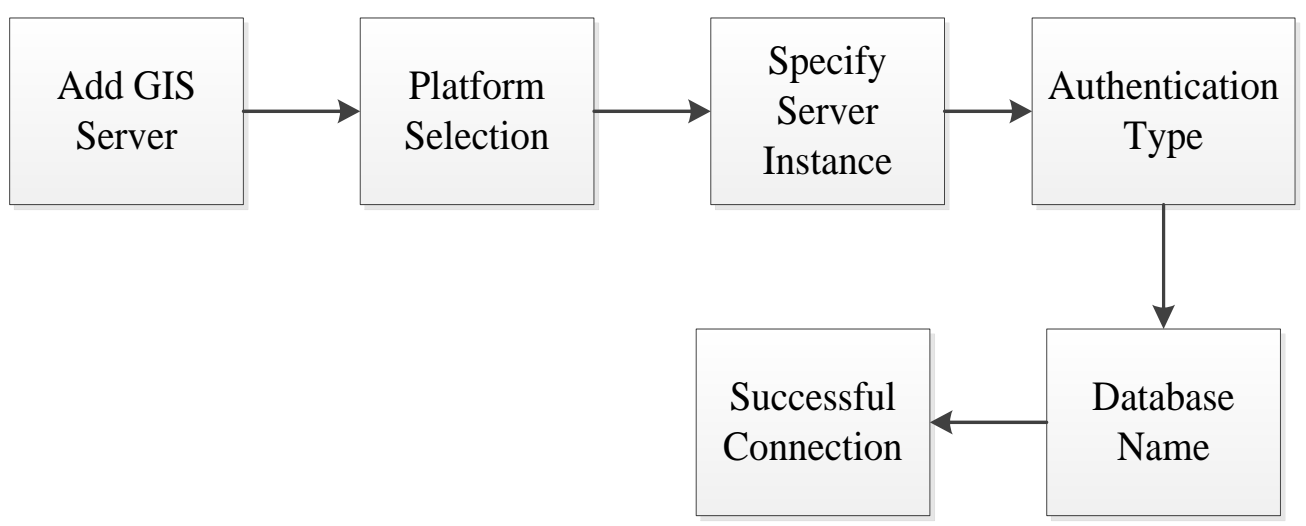

Figure 5.4: ArcGIS GIS Server Connection Workflow

The database connection establishes the publishing map documents, feature classes, and tables as services were possible. When sharing data option was chosen, this lead to the connection to the database for the information, which was accessed through a Universal Resource Locator (URL).

To enable editing of data on ArcGIS server it was required for the data to be registered to the database that it was contained in. The registration allowed the server to adjust paths to data when publishing services, allowed the validation of approved services by the server administrator, to prevent the copying large sums of data onto the server, and tracking edits of datasets. Prior to registering data to a server it had read only permissions to setup access paths.

\subsubsection{Publishing Map and Feature Services}

With the connection to the GIS server created and the registration of data, feature classes were published to the server using ArcMap desktop. The map services that were published provided the ability to show maps, features, and attributes to applications using the ArcGIS platform. Figure 5.6 shows the process of publishing a service.

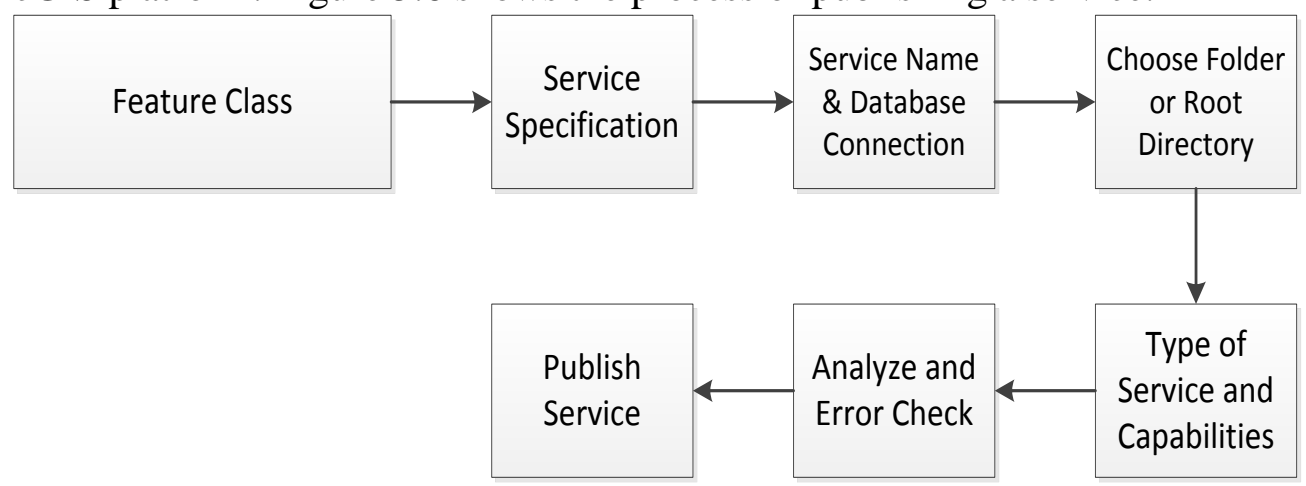

Figure 5.5: Service Publishing Workflow

From the file menu in ArcMap, share as was selected which brought up a dialog to publish data in the table of contents as a service. Following the process of publishing a service, a specific folder was advised to use for the end product. The service had many 
options that could be selected. The capabilities that were set were mapping and Keyhole Markup Language (KML). Mapping toggled the properties of URL, Data, Map, and Query. Under the KML section, options of separate images, single image, vectors, and Google Earth Output were chosen. Before publishing a service, an analysis of the layers in the service was performed to check for errors that impede performance, and found errors needed to be addressed before the service was allowed to be published.

The ArcGIS REST (Representational State Transfer) Services directory listed the services that have been published to and hosted by the ArcGIS Server. The hosted GIS services enabled the connection between the webmap application and the geodatabase through the Internet. Figure 5.7 shows the four published map services and two published feature services.

ArcGIS REST Services Directory
Home $>$ services $>$ brandon nilsson
ISON I SOAP

\section{Folder: brandon_nilsson}

Current Version: 10.11

View Footprints In: ArcGIS.com Map

Services:

- brandon nilsson/PrivateArtifactsFService (FeatureServer)

- brandon nilsson/PrivateArtifactsFService (MapServer)

- brandon nilsson/PrivateArtifactsMap (MapServer)

- brandon nilsson/PublicArtifactsFService (FeatureServer)

- brandon nilsson/PublicArtifactsFService (MapServer)

- brandon nilsson/PublicArtifactsMap (MapServer)

\section{Supported Interfaces: $\underline{\text { REST }} \underline{\text { SOAP }} \underline{\text { Sitemap Geo Sitemap }}$}

Figure 5.6: ArcGIS Rest Services Directory

\subsubsection{Webmap Application Development}

The application was designed using the Adobe Flex framework which used the Adobe Flash Builder as the Integrated Development Environment (IDE), the Flex Software Development Kit (SDK) 4.6, and the Esri ArcGIS API for Flex 3.4. The Flex framework was decided upon for its ability to develop complex functionality and rich data visualization.

The web map application component incorporated the map services. The application focused on the nations of the world and the initial extent of the map was set to enable viewing of all nations simultaneously when the application was launched. Figure 5.8 shows the application with the artifact features received using the map services. 


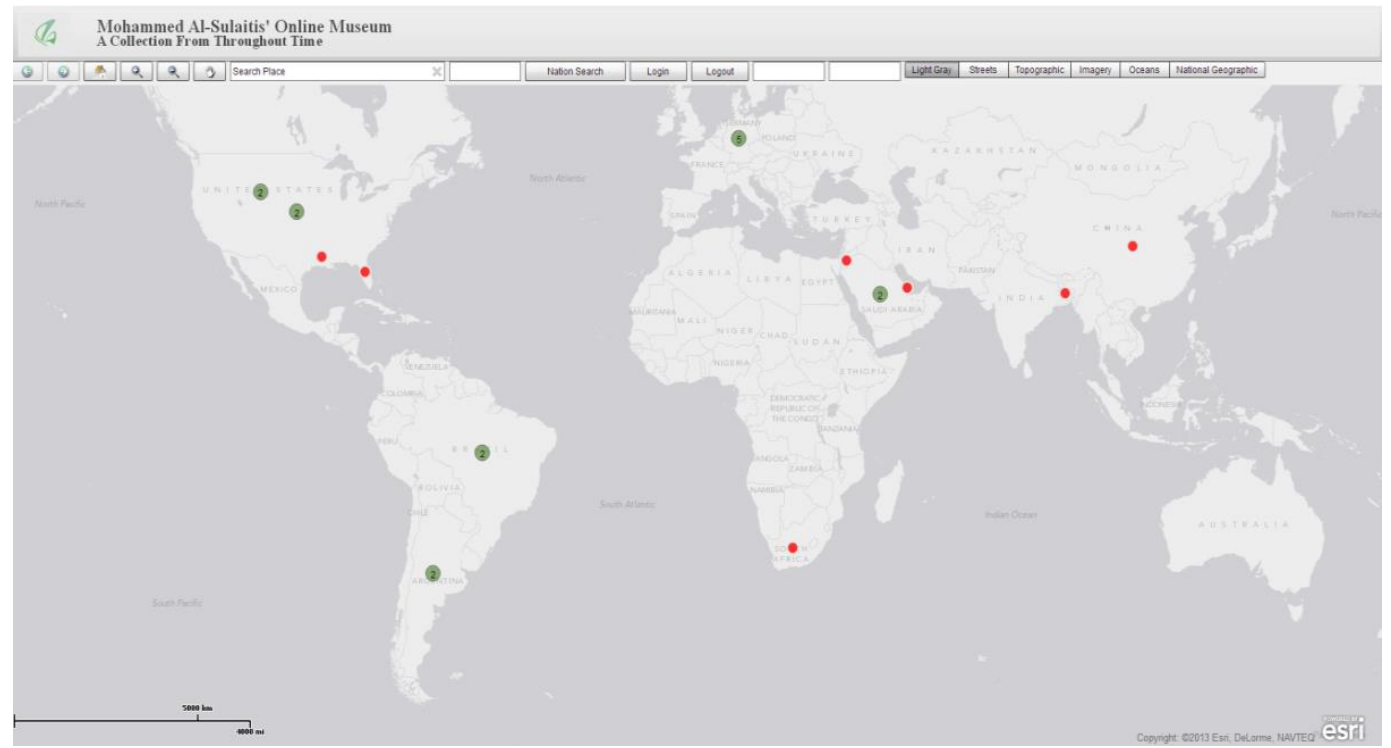

Figure 5.7: Webmap Application Lanuch

The application consumed two types of map service layers: The ArcGISTiledMapServiceLayer and the published Feature layer. The ArcGISTiledMapServiceLayer allowed for the use of cached map services from ArcGIS Online for use as basemaps in the application. The basemaps included were Light Grey Canvas, World Street Map, World Topo Map, World Imagery, Ocean Basemap, and National Geographic World Map. The feature layer allowed the information in the feature services to be displayed effectively and efficiently on users computer. Feature layers had display modes that changed how they were seen when loaded. For this application snapshot mode was decided upon because it retrieved all features within the map service at once. Snapshot mode was used for all services that were used in the web application.

The medium of the display of the artifact data collected by Mohammed Al-Sulaiti in the form of a datagrid and the map in an efficient manner was the goal of the application. The goal of creating a datagrid based on user input was achieved by using the Query and QueryTask components of the ArcGIS Flex API.

To populate the chart with information from the published services, Query and QueryTask components were used. The Query component was used to retrieve records meeting the QueryTask parameters. The results were then put in the datagrid and shown to the user. This was implemented by using a text input box and a button that performed the query.

\subsection{Login for Private users}

The service that was created to act as the login service for the project was created with XML sheets. The login service contained a table that held all allowed users to the private section. The login information was split into a username and a password which were provided by the user and checked by the login service. When a user inputs a username and a password, the XML file is queried to check if the pair existed. If the username and password is contained within the table, it returns a success flag to the Flex application 
and the user successfully logs in. If logging in was successful the username and password text boxes are no longer enabled as well as the login button.

\subsection{Summary}

This chapter elaborated on the implementation of the project. Section 5.1 went on the details in the development of the geodatase, with the process of data loading, and application development. Section 5,2 explained the development of the application and the steps to create services, connections to GIS servers, database and data registration, and the Flex application development. 



\section{Chapter 6 - Use Case}

The fundamental purpose of this project was developing an application to simply and effortlessly communicate the artifact data to the public. The web map application assisted Mohammed Al-Sulaiti and the public to see and interpret the artifact collection. This chapter conveys the use cases for the designed application. Section 6.1 explains the applications graphical user interface (GUI). Section 6.2 illustrates how Mohammed AlSulaiti and the public can query, display, and analyze information of the artifacts contained in each individual point. Section 6.3 explains the difference between being logged in as a private user and being a public user. Section 6.4 explains the client only editing application. Section 6.5 summarizes the chapter.

\subsection{Graphic User Interface}

The GUI was designed for clarity and regularity by putting components of similar functions next to one another. The design allowed for commonplace tasks to be done with ease. Figure 6.1 shows the layout of the application's GUI and map.

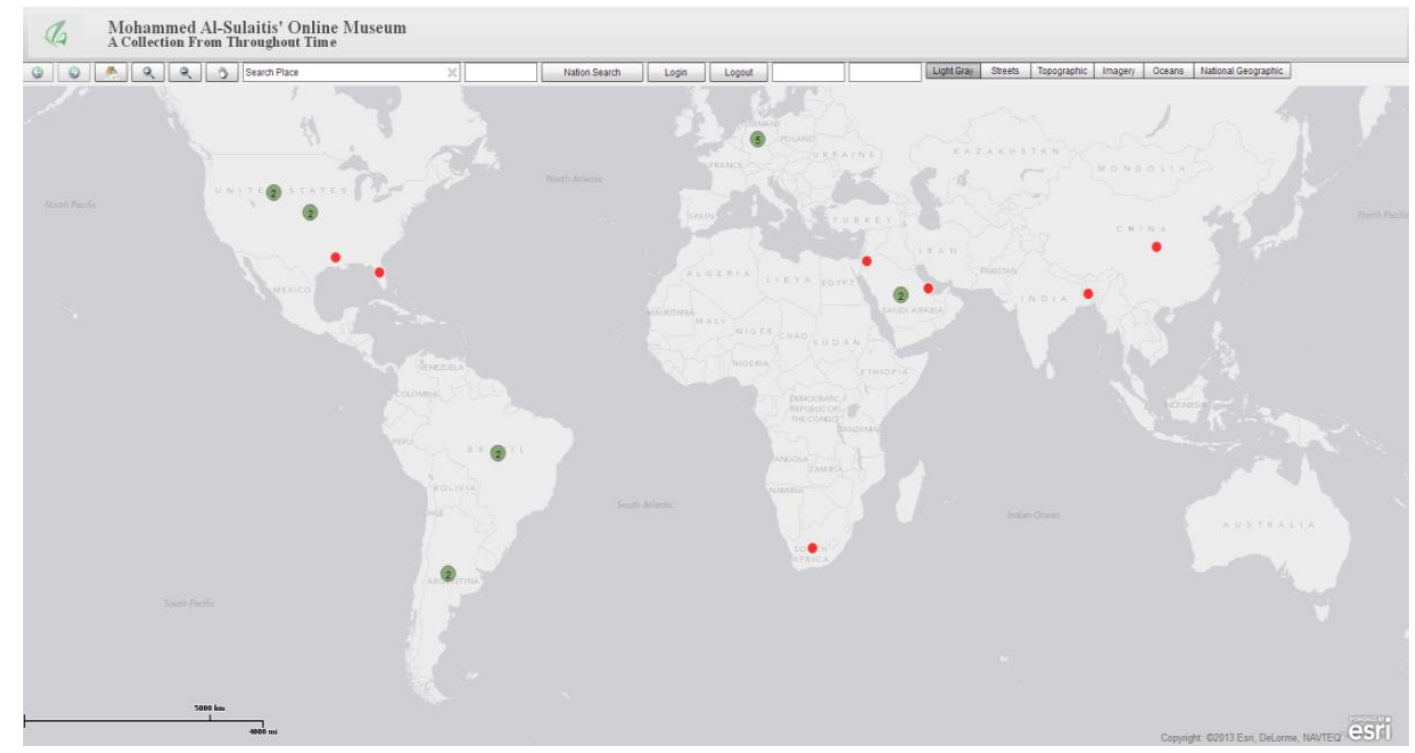

Figure 6.1: Application and Graphic User Interface

Table 6.1 elaborates on the functions of each button and text box that is contained on the toolbar. With the toolbar, a user can zoom-in and zoom out the map view, visualize data in a grid, search for a place, change basemaps, and login or logout. Searching for a place was created with an Esri geocoder. This tool allowed the user to type in a place name and the geocoder would zoom to that location on the map. This was implemented to allow users to search areas of interest for where artifacts are from. 
Table 6.1: Application Toolbar

\begin{tabular}{|c|c|c|c|c|c|c|}
\hline Content & Image & & & & & \\
\hline Navigation Tools & (2) & 艎 & Q. $][$ & & & \\
\hline Geocoder for Users & Search Place & & & $x$ & & \\
\hline Query Map Service & & & tinent Search & & & \\
\hline Login with username & Login & Logout & & & & \\
\hline Switch basemaps & Light Gray & Streets & Topographic & Imagery & Oceans & National Geographic \\
\hline
\end{tabular}

\subsection{Artifact Data}

Mohammed Al-Sulaiti was in the process of building a museum to house his physical collection. With his collection in a digital format, he would be able to visualize where his collection had come from. This visualization would be the public's eye into his collection for those outside of Qatar. When a user opened the application he or she would be shown the world with points referring to individual or clustered artifacts. Using the toolbar's zoom-in button or the geocoder, the user would be able to identify artifacts in areas of interest. For users with special access, they will be capable of logging in to see more of the collection that normal public users cannot. If the user is interested in a point, clicking the point will bring up a pop-up window showing the artifacts Name, Nation, Information, and Continent. This information is shown in figure 6.3. 


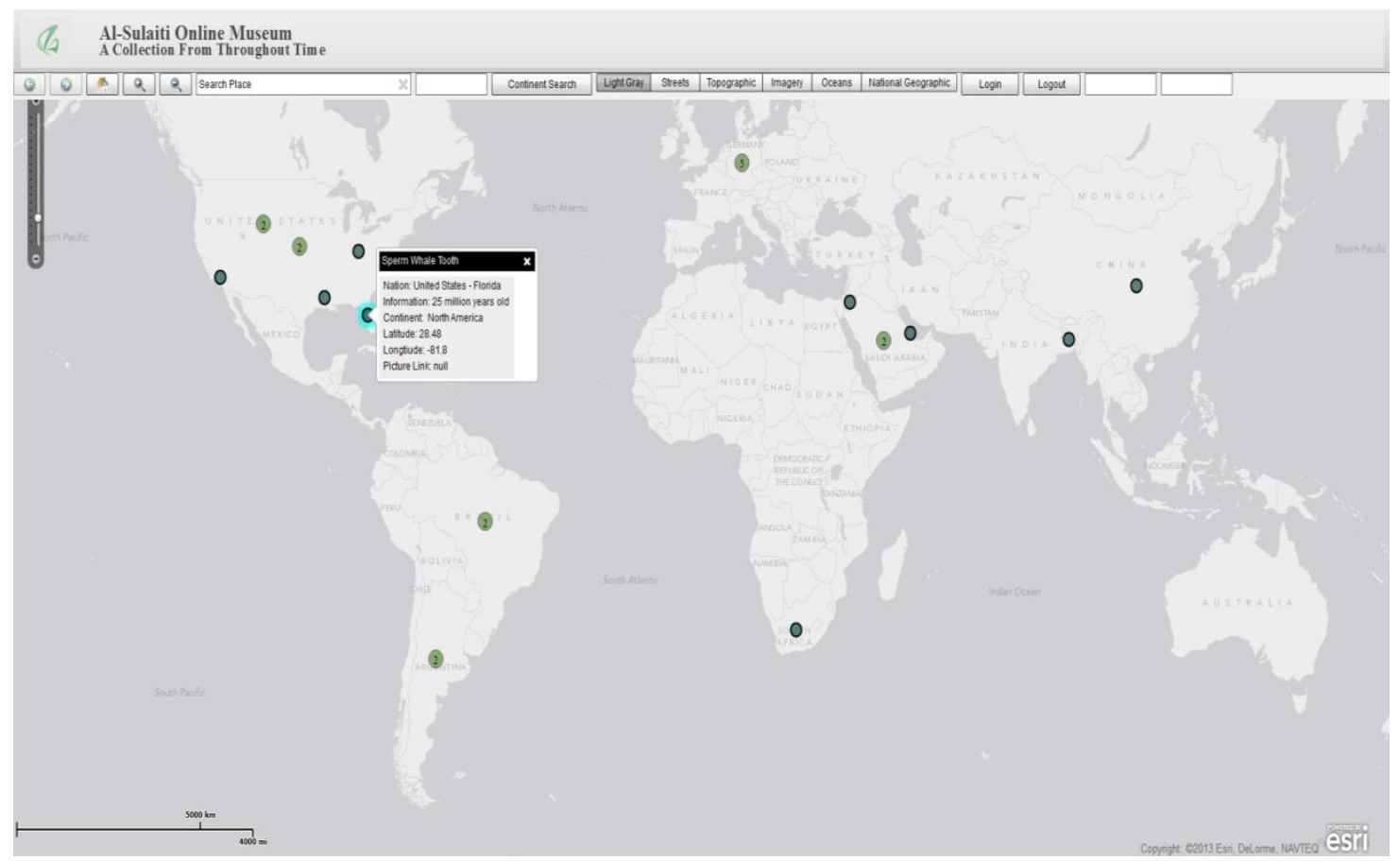

Figure 6.2: Point Selection

Following the selection of a point, the user could decide the continent that held the selection was of interest. Then he or she could search using the continent search to find all artifacts contained within the desired continent (Figure 6.4). This allowed for a very broad search and the ability to narrow down the information based upon what is requested by the user.

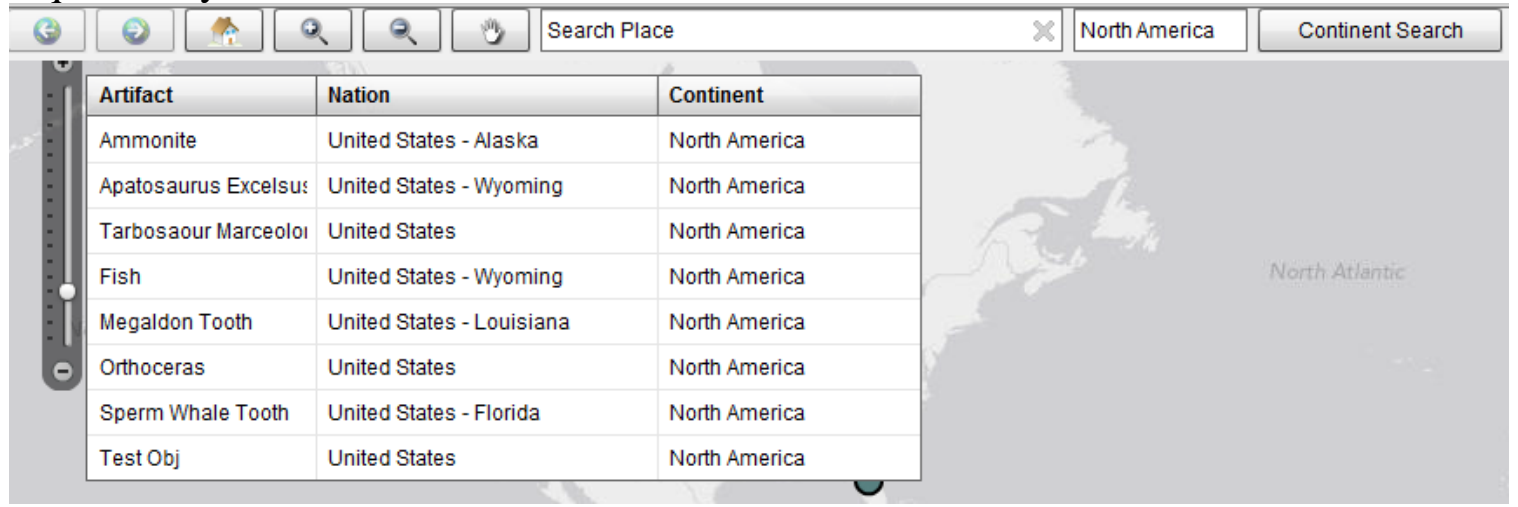

Figure 6.3: Query Results on continent

\subsection{Private Users}

Mohammed Al-Sulaiti needed a separation between users on what they were capable of viewing. It was decided upon that public viewers would only be allowed to view certain artifacts from his collection while private users would be able to view a larger selection of his collection. The capability of logging in to the user application was dictated by the Mohammed Al-Sulaiti. Mohammed Al-Sulaiti wanted the ability to add and remove 
people from seeing more of his collection. Figure 6.5 presents the difference in symbology color between the public and private users.

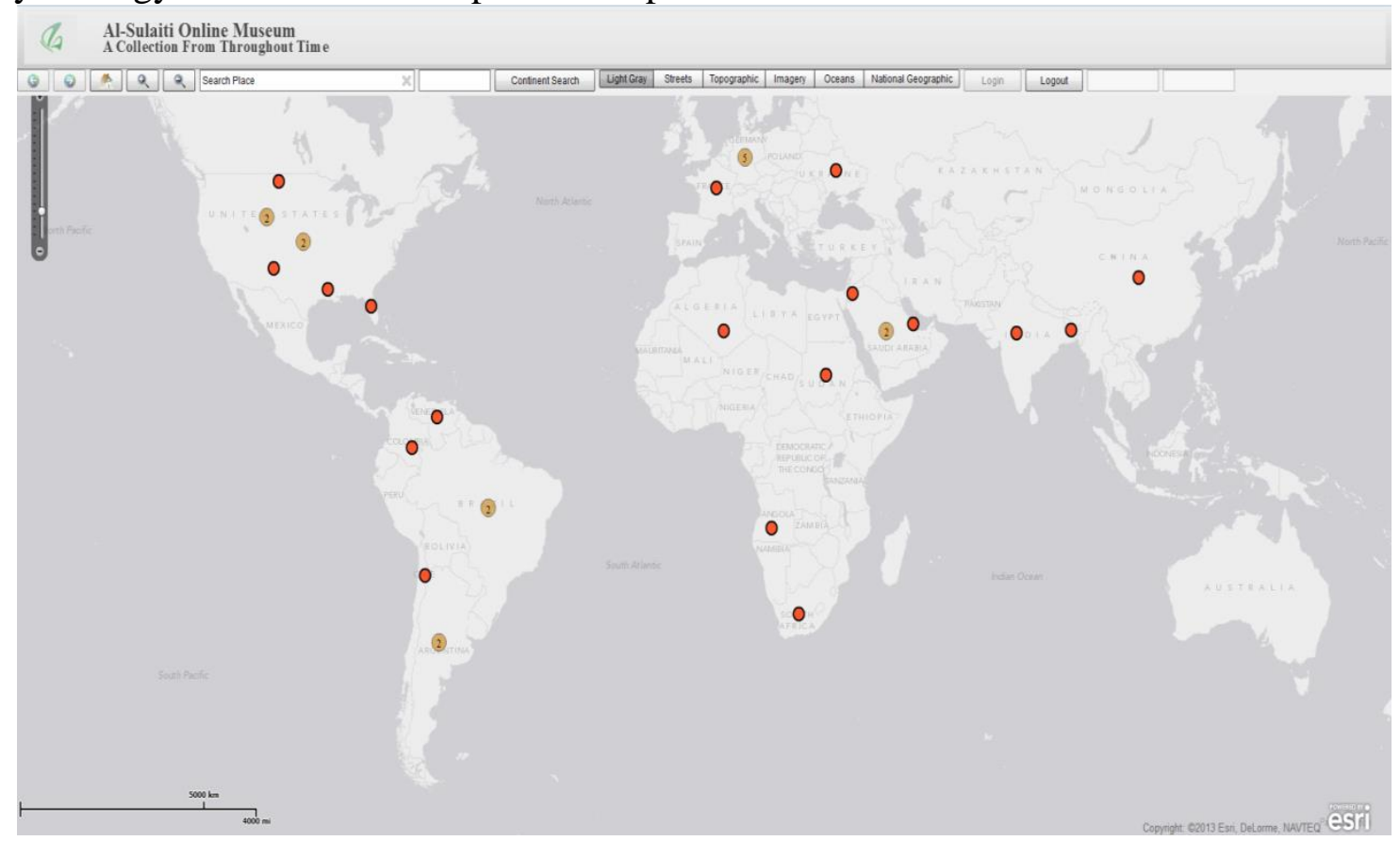

Figure 6.4: Private layer Symbology

When the application initially loaded, it was in the public view showing the layer available to the general public. The public users had the same functionality as private users did except for querying the layers to populate the datagrid.

Once the application had loaded successfully the user with login information could input the username and password into the respective boxes. If the information they input was correct, the application would change the current visible layer. When the layers switched, the symbology was changed to signify that the user is seeing different information than prior. When the user called the query it shows information from the private layer.

\subsection{Data Editor Application}

For the client to be capable of modifying the information contained in the artifact dataset an editing application was developed. The editing application used feature services made from the feature classes and hosted by ArcGIS Server with SDE. The feature classes within the server, must have been registered as versioned to accept edits. The editing functionality required the use of ArcGIS Server with SDE. Figure 6.6 demonstrates what the client data editing application did. Mohammed Al-Sulaiti had the choice of adding points to the public or private datasets. A function was called on the basemap to obtain latitude and longitude values. The function was called when the user clicks on the map. The feature editor, like the public application, used a geocoder to find places, This was because a place might not be known to Mohammed and the ability to be able to find it and put context with a name was important. The geocoder also allowed for a much more accurate artifact placement in places that the user doesn't know about. 


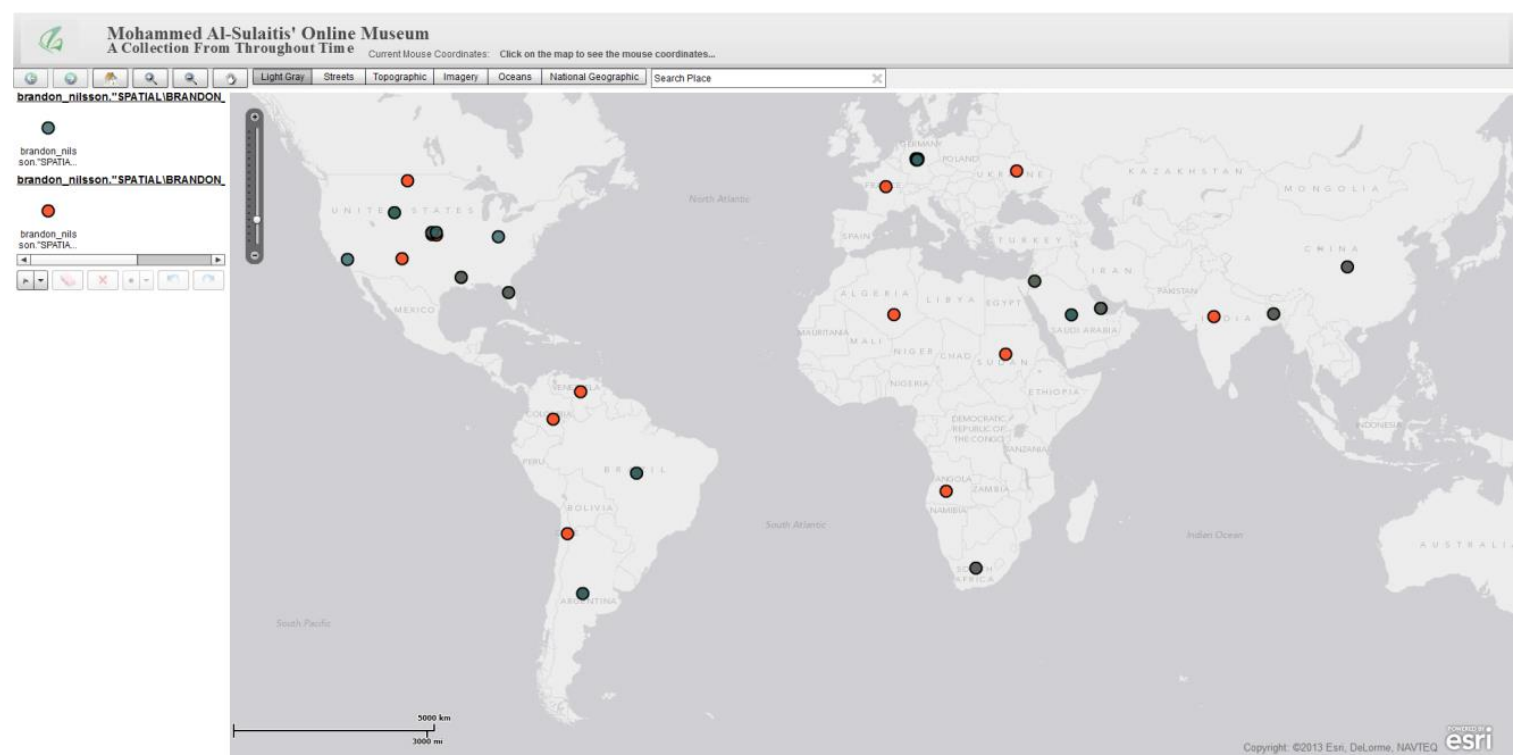

Figure 6.5: Editor Application Interface

\subsection{Summary}

This chapter explained the functions of the user interface and the use of the application for different circumstances. The first section went over how the public users queried and displayed data while the private users have to supply specific credentials to view different information. The second instance was the editing application for the client to edit, add, or remove data from the collection. 



\section{Chapter 7 - Conclusions and Future Work}

This project was designed for Mohammed Al-Sulaitis' collection. Mohammed Al-Sulaiti needed a way to show his collection of artifacts to the public in an easy to understand manner.

In the early stages of the project, an analysis of the requirements was conducted to determine function and non-functional requirements. An inspection of similar institutions and their approaches was done. With the linking of information from both analyses, a web-based mapping application was designed to show Mohammed Al-Sulaiti's data to the public. The application allowed the client and users to visualize, query, and research from the collection.

The data provided by the client was written into a temporary access database to define the fields and their respective formats. Proper aliases were attributed to the fields to ensure that they were understandable when read. A file geodatabase schema was designed to accommodate the data and the feature classes that the data were to fit into. The artifact data were geocoded at a national level based off of the information given.

Shapefiles were created using the datasets created with the temporary Microsoft Access Database. The shapefiles were then made into feature classes and brought into ArcGIS Server for publishing. The datasets were registered as versioned with the database and were published with ArcGIS 10.1 for Server with SDE as map services and feature services, which enabled the data to be viewed across the Internet. With the created web application, Mohammed Al-Sulaiti and general users were able to perform queries on the artifacts, and view the collection.

The web-map application was created using Adobe Flex, Adobe Flash Builder as an IDE joined with the Adobe Flex SDK, incorporating the Esri ArcGIS API for Flex 3.4 to design interactive and complex web applications. Mohammed Al-Sulaiti and the public users could access the application using a web browser with Adobe Flash Player 11, or higher, plugin installed.

The application allowed Mohammed Al-Sulaiti to grant easy access to his collection for users that were interested. It also presented how a web-map application could be used to organize, view, visualize, and share private collections to the public.

The developed application created the ground work visualizing Mohammed AlSulaiti's collection. Components could be developed to enhance the functionality of the application or add to it. An example of additional functionality such as temporal modeling provided the ability to study the association of time and area where artifacts were found. This application could be used by any private or public collector with a desire to show their collection. Additionally with the use of 3D modeling and blue prints of museums, the ability to explore the interior of a museum and view the collection over the Internet. 



\section{Works Cited}

Baumann, J. (2011, January). A New Dimension. Retrieved 7/14/2013, from ESRI: http://www.esri.com/news/arcuser/0111/tufts.html

Boyd, P. D. (2002, February, 2). Peter D. A. Boyd's GIS in Museums. Retrieved 4/13/2013, from GIS in Museums - a case study. In Access to Better Information. Association for Geographic Information Conference Proceedings 1999, 8.9.18.9.7.: http://www.peterboyd.com/AGI99.htm

Fu, P., \& Jiulin, S. (2011). Web GIS: Principles and Applications. Redlands: ESRI Press. Jones, G., \& Christal, M. (2002). The Future of Virtual Museums: On-Line, Immersive, $3 D$ Environments. Austin, Texas.

Kelly, A. K. (2005, July, 13). HG 33 Book Final. Retrieved 9/12/2013, from Historical Geography: http://www.historical-geography.net/volume_33_2005/knowles.pdf

Law, R. (n.d.). Information Technology Applications in Hospitality and Tourism: A Review of Publications from 2005 - 2007. Journal of Travel \& Tourism Marketing, 36.

Mikhailovna, I. M., \& Vikentevich, S. K. (2004). Museology - an Instrument for Unity and Diversity? Zentrum München: Museums-Pädagogisches.

Powdermill Nature Reserve. (2006). Retrieved 8/15/2013, from Carnegie Museum of Natural History: http://www.carnegiemnh.org/science/default.aspx?id=17555

Schweibenz, W. (1998). The "Virtual Museum":New Perspectives For Museums to Present Objects and Information Using the Internet as a Knowledge Base and Communication System. Saarbrücken: University of Saarland, Germany.

Woert, A. v. (2011). GIS Use in The Reinterpreation of Archaeological Museum Collections: The Combs Site, Boulder Utah. Chico: California State University, Chico. 



\section{Appendix A. MXML Application}

This is the application and the Adobe Flex, ActionScript, and MXML code that was used in creating the application.

$<$ ?xml version="1.0" encoding="utf-8"?>

<s:Application xmlns:fx="http://ns.adobe.com/mxml/2009"

xmlns:s="library://ns.adobe.com/flex/spark"

xmlns:mx="library://ns.adobe.com/flex/mx"

xmlns:esri="http://www.esri.com/2008/ags"

xmlns:supportClasses="com.esri.ags.skins.supportClasses.*"

pageTitle="Qatar Online Museum"

$<\mathrm{fx}:$ Metadata $>$

$</$ fx:Metadata $>$

$<$ fx:Script $>$

$<![C D A T A[$

import com.esri.ags.FeatureSet;

import com.esri.ags.Graphic;

import com.esri.ags.esri_internal;

import com.esri.ags.events.LayerEvent;

import com.esri.ags.geometry.Extent;

import com.esri.ags.geometry.MapPoint;

import com.esri.ags.geometry.Polygon;

import com.esri.ags.layers.FeatureLayer;

import com.esri.ags.layers.TiledMapServiceLayer;

import com.esri.ags.tools.NavigationTool;

import mx.collections.ArrayCollection;

import mx.collections.ArrayList;

import mx.collections.ListCollectionView;

import mx.controls.Alert;

import mx.core.mx_internal;

import mx.events.FlexEvent;

import mx.managers.DragManager;

import mx.rpc.events.FaultEvent;

import mx.rpc.events. ResultEvent;

import mx.rpc.http.mxml.HTTPService;

import mx.rpc.xml.*;

import mx.utils.*;

import spark.events.ListEvent;

//value to ensure only a single login is used at a time

private var logged: int $=0$;

/lempty XML variable setup to contain an outside XML file

private var fileXML:XML $=$ new XML

/*Login Capability Code 


\section{Going Here*/}

private function onload(event:ResultEvent):void

\{

fileXML = new XML (event.result);

//Alert.show(item);

for each (var item:XML in fileXML.User)

\{

I/check if the values in username and password are the same returning only true

or false

// if true change layer visability, disable the text input boxes and login button

if (item.login==username.text \&\& item.password== password.text)

\{

points.visible=!points.visible

privatePoints.visible=! privatePoints. visible

logged $=1$

Alert.show("Login Successful")

priv.enabled=! priv.enabled

username.text="'"

password.text="'"

username.enabled=! username.enabled

password.enabled=! password.enabled

break;

\}

\}

\}

protected function sign_in(event:MouseEvent):void

\{

\}

//bring in the XML file located at a specific URL

loginXML.send(event)

protected function sign_out(event:MouseEvent):void

\{

//logout only if the value of logged is equal to 1 if its not alert the user

if $($ logged $==1)$ \{

Alert.show("Logout Successful");

logged $==0$

priv.enabled $=$ ! priv.enabled

username.enabled $=$ ! username.enabled

password.enabled $=$ ! password.enabled

points.visible $=$ ! points. visible

privatePoints.visible $=$ ! privatePoints. visible

\} else if (logged $==0)\{$

Alert.show("You're not currently signed in");

\}

protected function loginService_faultHandler(event:FaultEvent):void

\{

Alert.show(event.fault.message);

\}

/* Login Capability Code 


\section{Ends here*/}

protected function doQuery():void

\{

datagrid

//query the feature layers for specific information to populate a

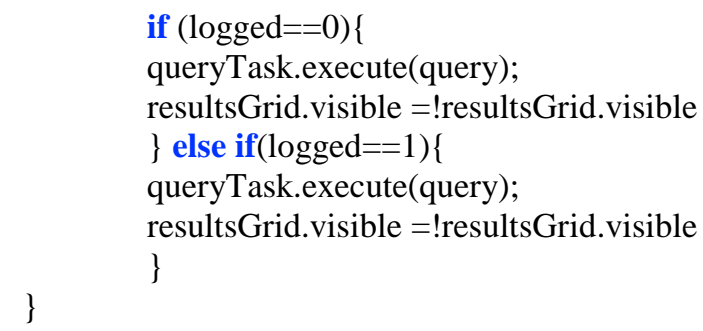

//Source: https://developers.arcgis.com/en/flex/sample-code/switching-

basemaps.htm

base map

\section{private function layerShowHandler(event:FlexEvent):void \\ \{ \\ // update the LODs/zoomslider to use/show the levels for the selected}

var tiledLayer:TiledMapServiceLayer = event.target as TiledMapServiceLayer; myMap.lods = tiledLayer.tileInfo.lods; \}

]]>

$</ f x:$ Script $>$

$<$ fx:Style>

@ namespace s "library://ns.adobe.com/flex/spark";

@ namespace mx "library://ns.adobe.com/flex/mx";

$</$ fx:Style $>$

$<\mathrm{fx}:$ Declarations $>$

$<$ !-- Place non-visual elements (e.g., services, value objects) here -->

<esri:NavigationTool id="navTool" map=" $\{$ myMap $\} " />$

$<$ !-- color used when a point is selected on the map -->

<esri:SimpleFillSymbol id="selSymbol"

</esri:SimpleFillSymbol>

$$
\begin{aligned}
& \text { style="solid" } \\
& \text { color="0x22BB99" } \\
& \text { alpha="1"> }
\end{aligned}
$$

$<$ !-- area for the definition of the symbol used for clustering symbology and how many

points one may contain -->

<!-- Source: https://developers.arcgis.com/en/flex/sample-code/clustering.htm -->

<esri:FlareSymbol id="flareSymbol"

backgroundAlphas $="[0.7,1.0] "$

backgroundColor="0x394B8C"

backgroundColors="[0x5B8C3E,0xBF2827]"

borderColor="0x666666" 


\author{
flareMaxCount="30" \\ flareSizeIncOnRollOver="3" \\ sizes $="[20,30] "$ \\ weights="[30,60]"/>
}

$<!--$ the clusterer function that is used by the feature layers for the new symbology -->

$<$ !-- Source: https://developers.arcgis.com/en/flex/sample-code/clustering.htm -->

<esri:WeightedClusterer id="clusterer"

sizeInPixels="25"

symbol=" $\{$ flareSymbol $\} " />$

<!-- Source: https://developers.arcgis.com/en/flex/sample-code/clustering.htm -->

$<$ esri:FlareSymbol id="flareSymbolPriv"

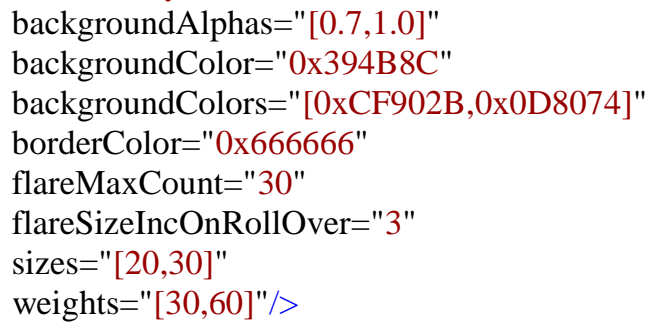

$<!--$ the clusterer function that is used by the feature layers for the new symbology -->

$<$ !-- Source: https://developers.arcgis.com/en/flex/sample-code/clustering.htm -->

$<$ esri:WeightedClusterer id="clustererPriv"

sizeInPixels="25"

symbol=" \{flareSymbolPriv $\} " />$

$<$ !-- specified color for the public symbol-->

<esri:SimpleMarkerSymbol id="defaultsym" alpha $=" 0.8 "$ color="0x336666">

<esri:SimpleLineSymbol width="2" color="0x000000"/>

$</$ esri:SimpleMarkerSymbol>

$<$ !-- specified color for the private symbol-->

$<$ esri:SimpleMarkerSymbol id="privateSym" alpha $=" 0.8 "$

color="0xFF3300">

<esri:SimpleLineSymbol width="2" color="0x000000"/>

$<$ esri:SimpleMarkerSymbol>

$<!--$ query task for the private artifact layer -->

$<$ esri:QueryTask id="queryTaskPrivate"

url="http://msgis-agsdev-

1:6080/arcgis/rest/services/brandon_nilsson/PrivateArtifactsMap/MapServer/0"

use $\mathrm{AMF}="$ true"/>

$<!--$ query task for the public artifact layer -->

<esri:QueryTask id="queryTask"

url="http://msgis-agsdev-

1:6080/arcgis/rest/services/brandon_nilsson/PublicArtifactsMap/MapServer/0"

use $\mathrm{AMF}="$ true"/>

$<!--$ query constaints based upon user input -->

<esri:Query id="query" where $=$ "Continent $=$ '\{contName.text $\}$ ""

outFields="[Artifact,NAME,Continent]"/> 
<!-- HTTPService call to XML file, at a specific url, for login information -->

result="onload(event)" />

$<$ s:HTTPService id="loginXML" resultFormat="e4x" url="extras/queryArt.xml"

$</ f x:$ Declarations $>$

<!-- Title bar with logo symbol, name and subtitle of the museum-->

$<\mathrm{s}$ :controlBarLayout>

$<\mathrm{s}$ :HorizontalLayout horizontalAlign="center"

paddingBottom $=" 5 "$

paddingTop="5"/>

$</$ s:controlBarLayout $>$

$<$ s:controlBarContent>

<s:SkinnableContainer id="HeaderBar" width="99\%" height="60" alpha="0.7"

fontWeight="normal" backgroundColor="\#F0F0F0" chromeColor="\#F0F0F0">

<s:Image id="Logo" y="3" left="4" width="70" height="54"

source="extras/benefits.png"

smooth="false"

toolTip="Museum Logo"

/>

<s:RichText id="Heading" y="13" left="110" width="100\%"

fontFamily="Times New Roman" fontSize="24" fontWeight="bold"

color="Black" text="Al-Sulaiti Online Museum"/>

<s:RichText id="SubHead" y="32" left="110" width="100\%"

fontFamily="Times New Roman" fontSize="20" fontWeight="bold"

color="Black" text="A Collection From Throughout Time" />

$</$ s:SkinnableContainer $>$

$</$ s:controlBarContent $>$

$<$ !-- canvas defined to take up any left over space not used by the title bar-->

$<\mathrm{mx}$ :Canvas id="myCanvas" width="100\%" height="100\%">

$<$ !-- definition of the map and what it is capable of -->

$<$ esri:Map id="myMap"

doubleClickZoomEnabled="true"

scaleBarVisible="true"

scrollWheelZoomEnabled="true"

wrapAround $180="$ true"

zoomSliderVisible="true"

panEnabled="true"

panArrowsVisible="false"

level="3">

basemaps.htm -->

<esri:center>

$</$ esri:center $>$

<esri:WebMercatorMapPoint lon="0" lat="0"/>

<!-- Source: https://developers.arcgis.com/en/flex/sample-code/switching-

<!-- Defining basemaps and what they are connected too to be displayed --> 
<esri:ArcGISTiledMapServiceLayer show="layerShowHandler(event)" url="http://server.arcgisonline.com/ArcGIS/rest/services/Canvas/World_Light_Gray_Base/MapServer" visible $="\{$ bb.selectedIndex $==0\} " />$

<esri:ArcGISTiledMapServiceLayer show="layerShowHandler(event)" url="http://server.arcgisonline.com/ArcGIS/rest/services/World_Street_Map/MapServer" visible $="\{$ bb.selectedIndex $==1\} " />$

<esri:ArcGISTiledMapServiceLayer show="layerShowHandler(event)" url="http://server.arcgisonline.com/ArcGIS/rest/services/World_Topo_Map/MapServer" visible $="\{$ bb.selectedIndex $==2\} " />$

<esri:ArcGISTiledMapServiceLayer show="layerShowHandler(event)" url="http://server.arcgisonline.com/ArcGIS/rest/services/World_Imagery/MapServer" visible $="\{$ bb.selectedIndex $==3\} " />$

<esri:ArcGISTiledMapServiceLayer show="layerShowHandler(event)" url="http://server.arcgisonline.com/ArcGIS/rest/services/Ocean_Basemap/MapServer" visible $="\{$ bb.selectedIndex $==4\} " />$ <esri:ArcGISTiledMapServiceLayer show="layerShowHandler(event)" url="http://server.arcgisonline.com/ArcGIS/rest/services/NatGeo_World_Map/MapServer" visible $="\{$ bb.selectedIndex $==5\} " />$ <esri:GraphicsLayer id="myGraphics" symbol=" $\{$ selSymbol $\}$ " />

$<$ !-- feature layer definition and what symobology that it uses which can be defined within code or ArcGIS Desktop --> <esri:FeatureLayer isEditable="false" id="points" mode="snapshot" outFields="*"

url="http://msgis-agsdev-

1:6080/arcgis/rest/services/brandon_nilsson/PublicArtifactsMap/MapServer/0" clusterer $="\{$ clusterer $\} "$ symbol=" $\{$ defaultsym $\} ">$ connected map service or feature service -- $>$

$<$ !-- information window renderer that is populated with data from the <esri:infoWindowRenderer>

$<\mathrm{fx}$ :Component $>$ 
<esri:LabelDataRenderer label=" $\{$ data.Artifact $\} ">$ $<$ s:BorderContainer

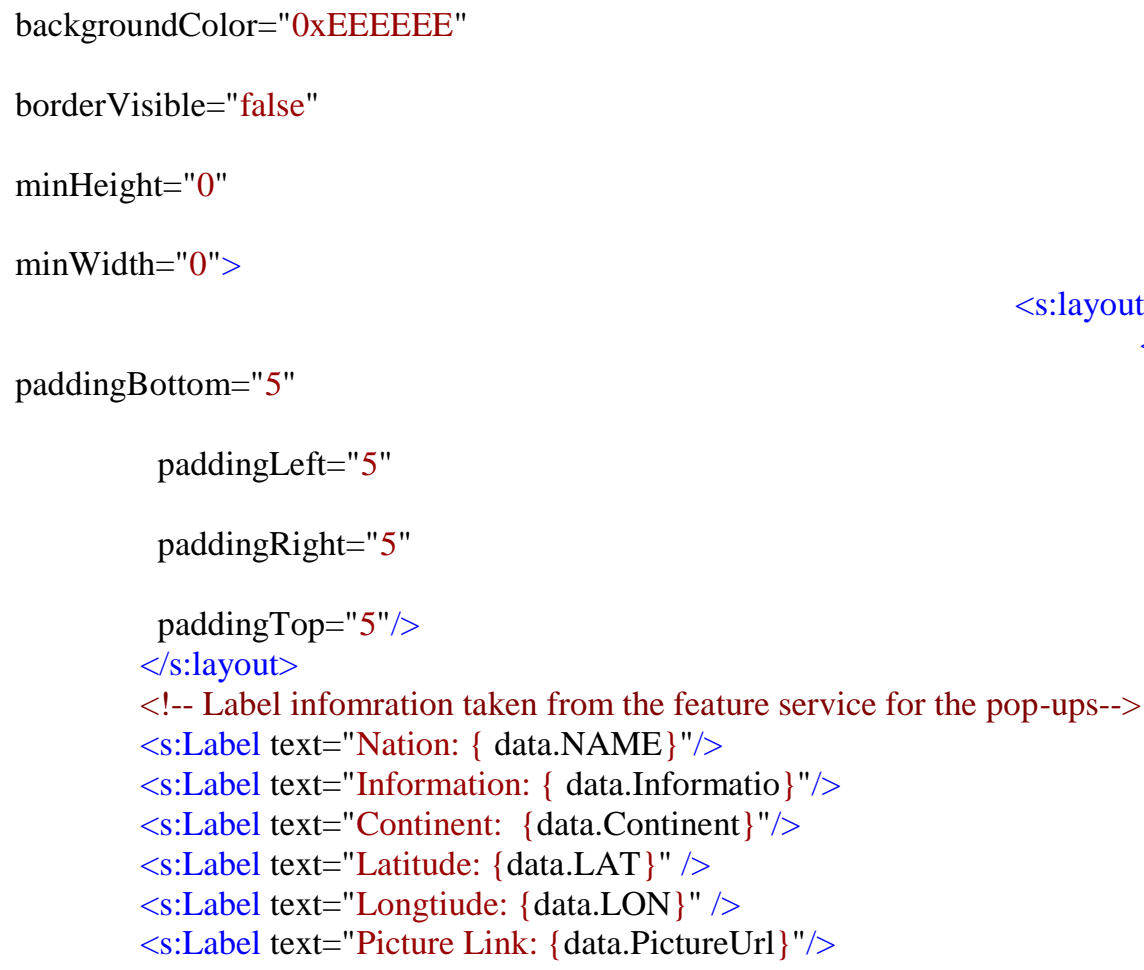




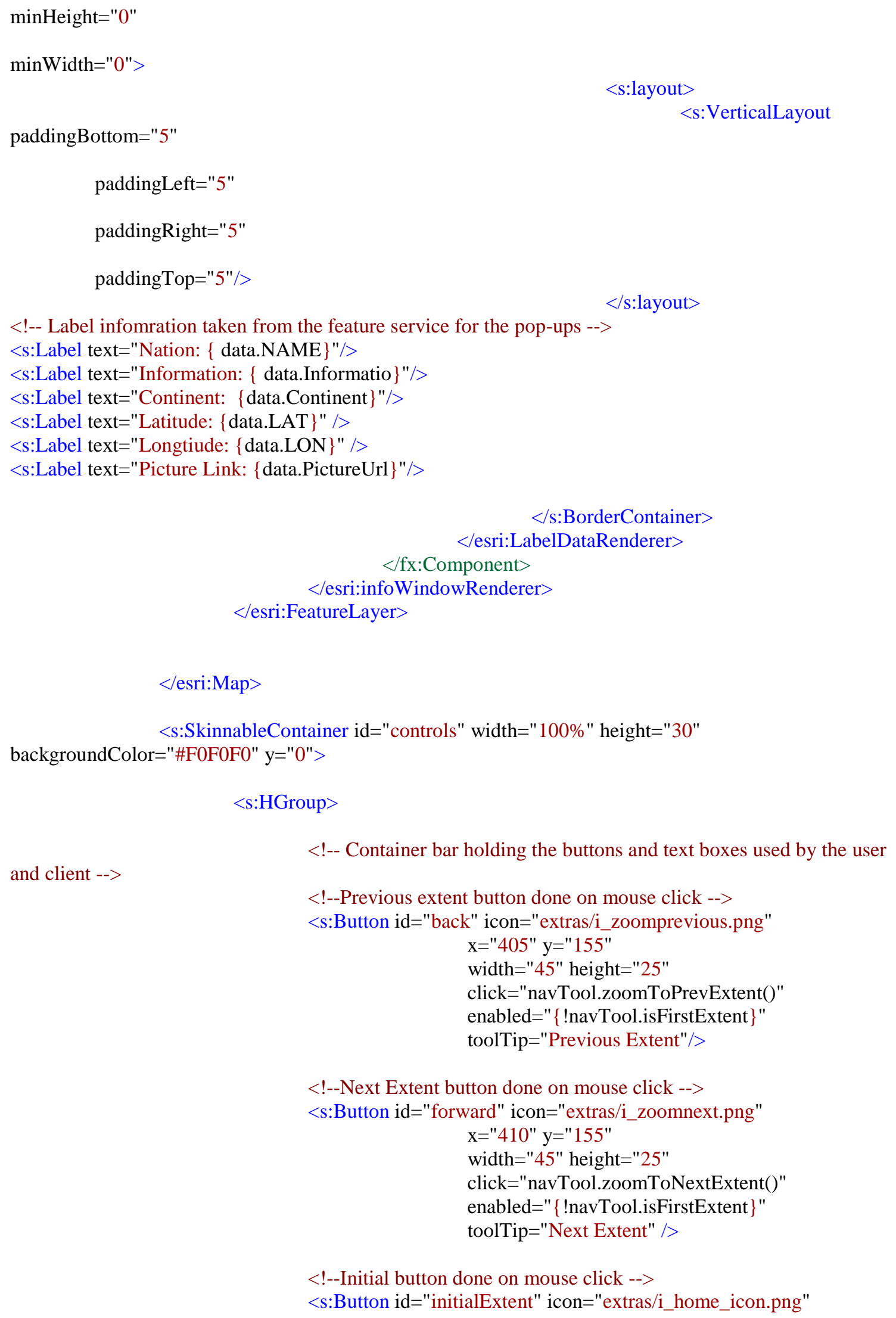




\section{Appendix B. Feature Editor Application}

This is the application and the Adobe Flex, ActionScript, and MXML code that was used in creating the feature editing application.

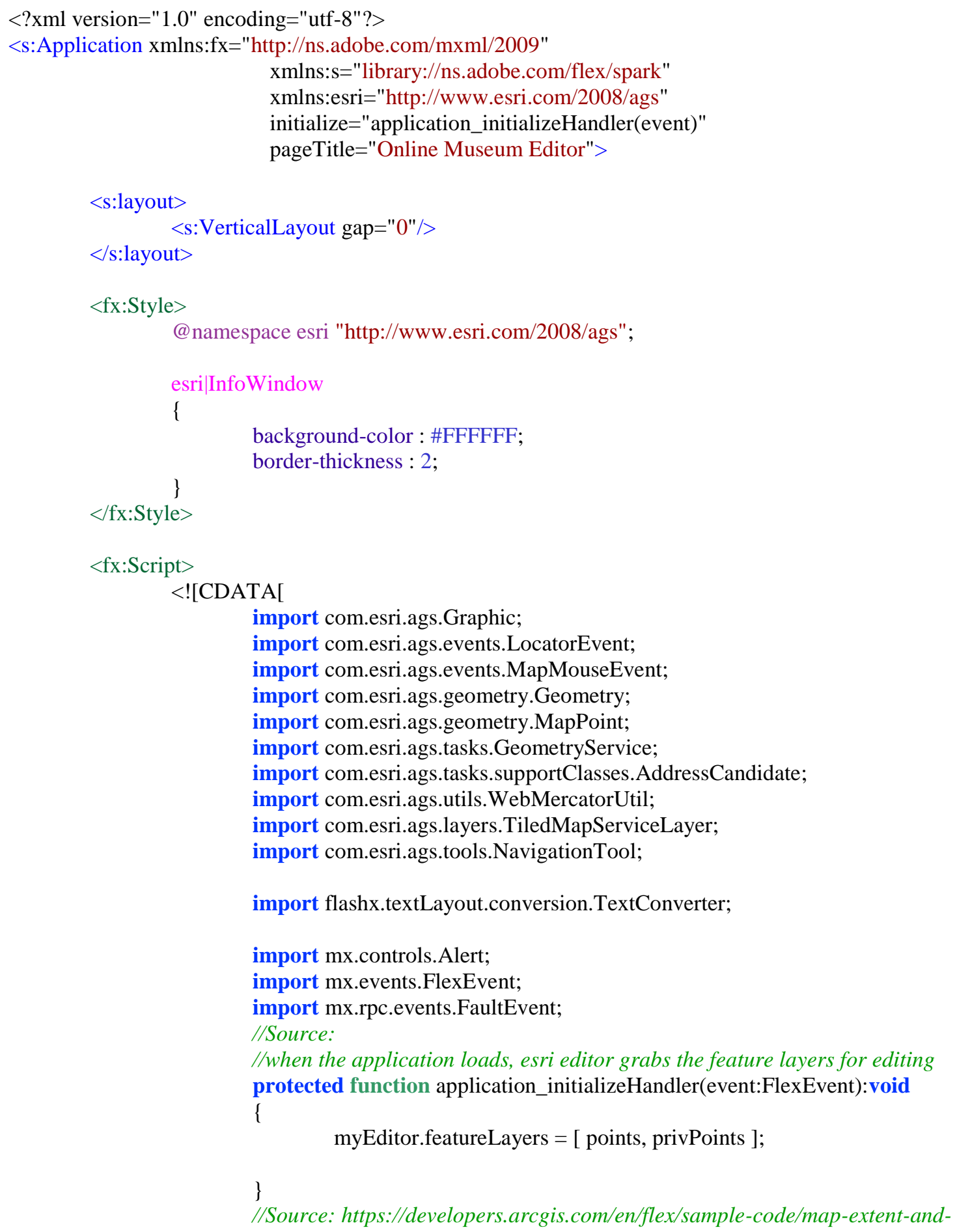


private function mapClickHandler(event:MouseEvent):void

\{

event.stageY);

const mapPoint:MapPoint = myMap.toMapFromStage $($ event.stageX,

const latlong:MapPoint $=$

WebMercatorUtil.webMercatorToGeographic(mapPoint) as MapPoint;

mousecoords.text $=$

"Latitude/Longitude is: " + latlong.y.toFixed(6)

\}

$+" / "+$ latlong.x.toFixed(6);

//Source: https://developers.arcgis.com/en/flex/sample-code/switching-

basemaps.htm

private function layerShowHandler(event:FlexEvent):void

\{

base map

// update the LODs/zoomslider to use/show the levels for the selected

TiledMapServiceLayer; var tiledLayer:TiledMapServiceLayer = event.target as

\} myMap.lods = tiledLayer.tileInfo.lods;

]]>

$</$ fx:Script $>$

$<\mathrm{fx}$ :Declarations $>$

<esri:NavigationTool id="navTool" map=" $\{$ myMap $\} " />$

$<$ !-- color used for public artifact points -->

<esri:SimpleMarkerSymbol id="defaultsym"

alpha $=" 0.8 "$

color="0x336666">

<esri:SimpleLineSymbol width="2" color="0x000000"/>

$</$ esri:SimpleMarkerSymbol>

$<$ !-- color used for private artifact points -->

<esri:SimpleMarkerSymbol id="privateSym"

alpha $=" 0.8 "$

color="0xFF3300">

<esri:SimpleLineSymbol width="2" color="0x000000"/>

$</$ esri:SimpleMarkerSymbol>

$</$ fx:Declarations $>$

$<$ !-- Title bar with logo symbol, name and subtitle of the museum-->

$<\mathrm{s}$ :controlBarLayout>

$<$ s:HorizontalLayout horizontalAlign="center"

paddingBottom=" $5 "$

paddingTop $=" 5 " />$

$</ s$ :controlBarLayout $>$

$<$ s:controlBarContent $>$

$<$ !-- Logo symbol of the museum-->

$<$ s:SkinnableContainer id="HeaderBar" width="99\%" height="60" alpha="0.7"

fontWeight="normal" backgroundColor="\#F0F0F0" chromeColor="\#F0F0F0">

<s:Image id="Logo" y="3" left="4" width="70" height="54"

source="extras/benefits.png" 


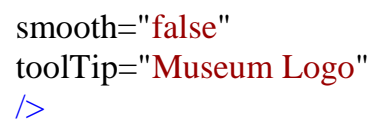

$<$ !-- Sub title of the museum--> $<$ s:RichText id="SubHead" y="32" left="110" width="100\%" fontFamily="Times New Roman" fontSize="20"

fontWeight="bold"

Time" /> color="Black" text="A Collection From Throughout coordinates.htm -->
<!-- where the mouse coordinates are placed when clicked within the map --> <s:Label x="444" y="43" text="Current Mouse Coordinates:"/> $<$ s:RichEditableText id="mousecoords" x="612" y="43" editable="false"

text="Click on the map to

see the mouse coordinates..." fontWeight="bold"/>

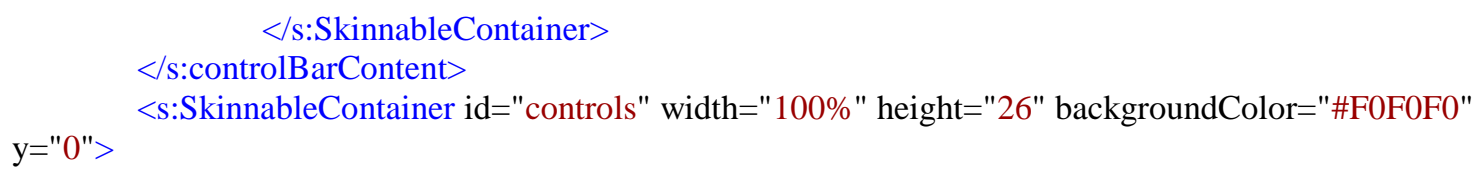

$<$ !--Zoom-in button done on mouse click -->

$<$ s:Button id="zoomIn" icon="extras/i_zoomin.png" 
$\mathrm{x}=" 420$ " $\mathrm{y}=" 155$ "

width="45" height="25"

click="navTool.activate(NavigationTool.ZOOM_IN)"

toolTip="Zoom In" />

$<$ !--Zoom-out button done on mouse click -->

$<$ s:Button id="zoomOut" icon="extras/i_zoomout.png"

$\mathrm{x}=" 425$ " $\mathrm{y}=" 155 "$

width $=" 45$ " height="25"

click="navTool.activate(NavigationTool.ZOOM_OUT)"

toolTip="Zoom Out" />

<!-- pan around the map based upon mouse click -->

$<$ s:Button id="Pan" icon="extras/i_pan.png"

$\mathrm{x}=" 430 " \mathrm{y}=" 155 "$

width $=" 45$ " height="25"

click="navTool.activate(NavigationTool.PAN)"

toolTip="Pan" />

<!-- Source: https://developers.arcgis.com/en/flex/sample-code/switching-basemaps.htm -->

$<\mathrm{s}$ :ButtonBar id="bb" x="520" y="155" requireSelection="true">

$<!--$ button bar that is connected to the base map layers provided by ArcGIS Online that were below up above -->

$<\mathrm{s}:$ dataProvider $>$

$<$ s:ArrayList>

$<\mathrm{fx}:$ String $>$ Light Gray $</ \mathrm{fx}:$ String $>$

$<$ fx:String $>$ Streets $</$ fx:String $>$

$<$ fx:String $>$ Topographic $</ \mathrm{fx}:$ String $>$

$<$ fx:String $>$ Imagery $</$ fx:String $>$

$<$ fx:String $>$ Oceans $</$ fx:String $>$

$</$ s:ArrayList $>$

$<\mathrm{fx}:$ String $>$ National Geographic $</ f x$ :String $>$

$</$ s:dataProvider $>$

$</$ s:ButtonBar $>$

Place"/>

<esri:Geocoder width="300" height="25" horizontalCenter="0" map=" $\{$ myMap $\} "$ text="Search

$</ s:$ HGroup $>$

$</ s:$ SkinnableContainer $>$

<s:HGroup width="100\%" height="100\%"

paddingLeft $=" 5 "$

paddingTop=" $5 ">$

<!--Source: https://developers.arcgis.com/en/flex/sample-code/editor-with-toolbar.htm --

$>$

$<$ !-- Editting functcionality encompasses the map and uses its feature layers -->

$<$ esri:Editor id="myEditor"

width="266"

geometryService $="\{$ new

GeometryService('http://sampleserver6.arcgisonline.com/arcgis/rest/services/Utilities/Geometry/Geo metryServer')\}"

map $="\{$ myMap $\} "$

toolbarVisible="true"

/>

$<!--$ definition of the map and what it is capable of --> 


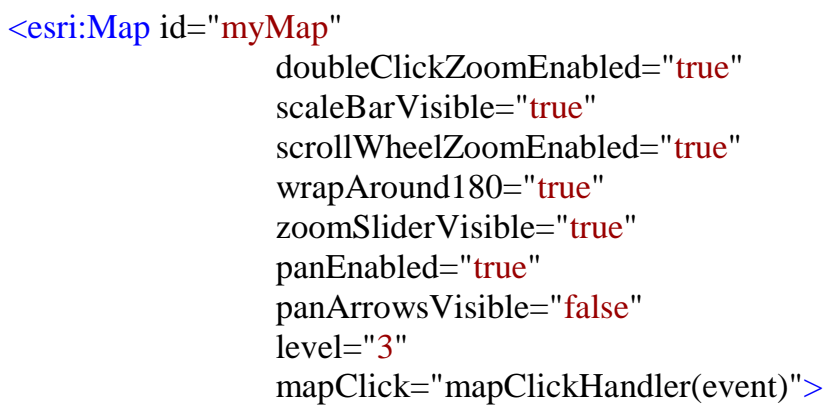




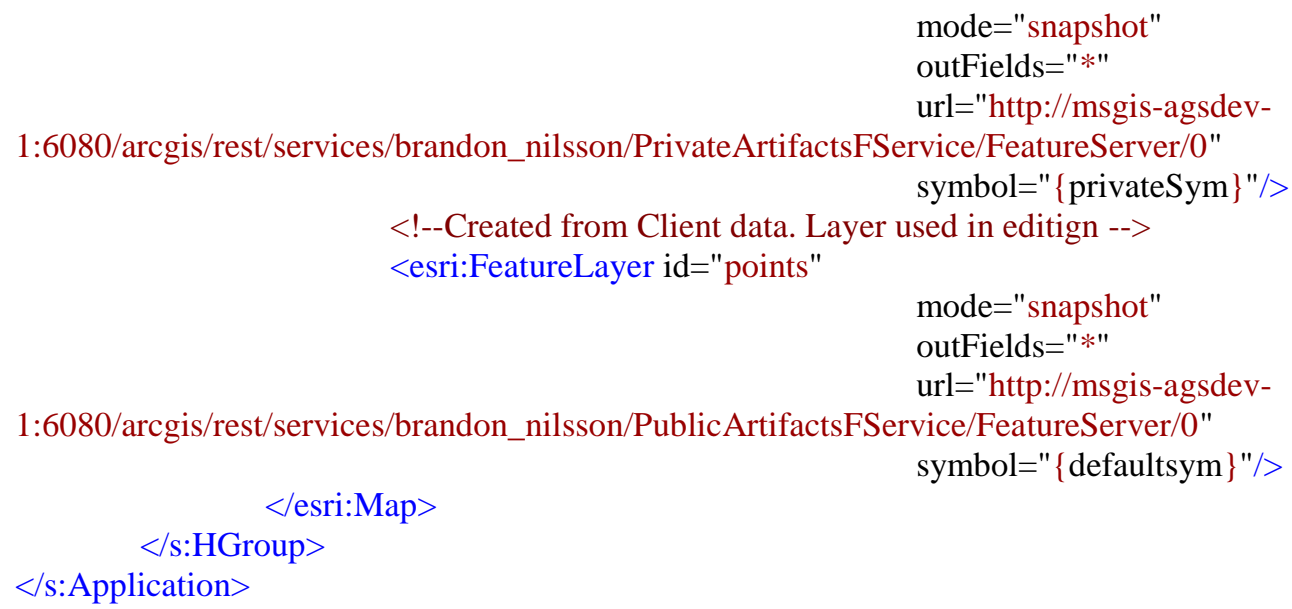

